PPPL-3036

UC-420,426,427

\title{
ROLE OF MHD ACTIVITY IN LH-ASSISTED DISCHARGES N THE PBX-M TOKAMAK
}

BY

M. TALVARD, R.E. BELL, S. BERNABEI, ET AL.

JANUARY 1995
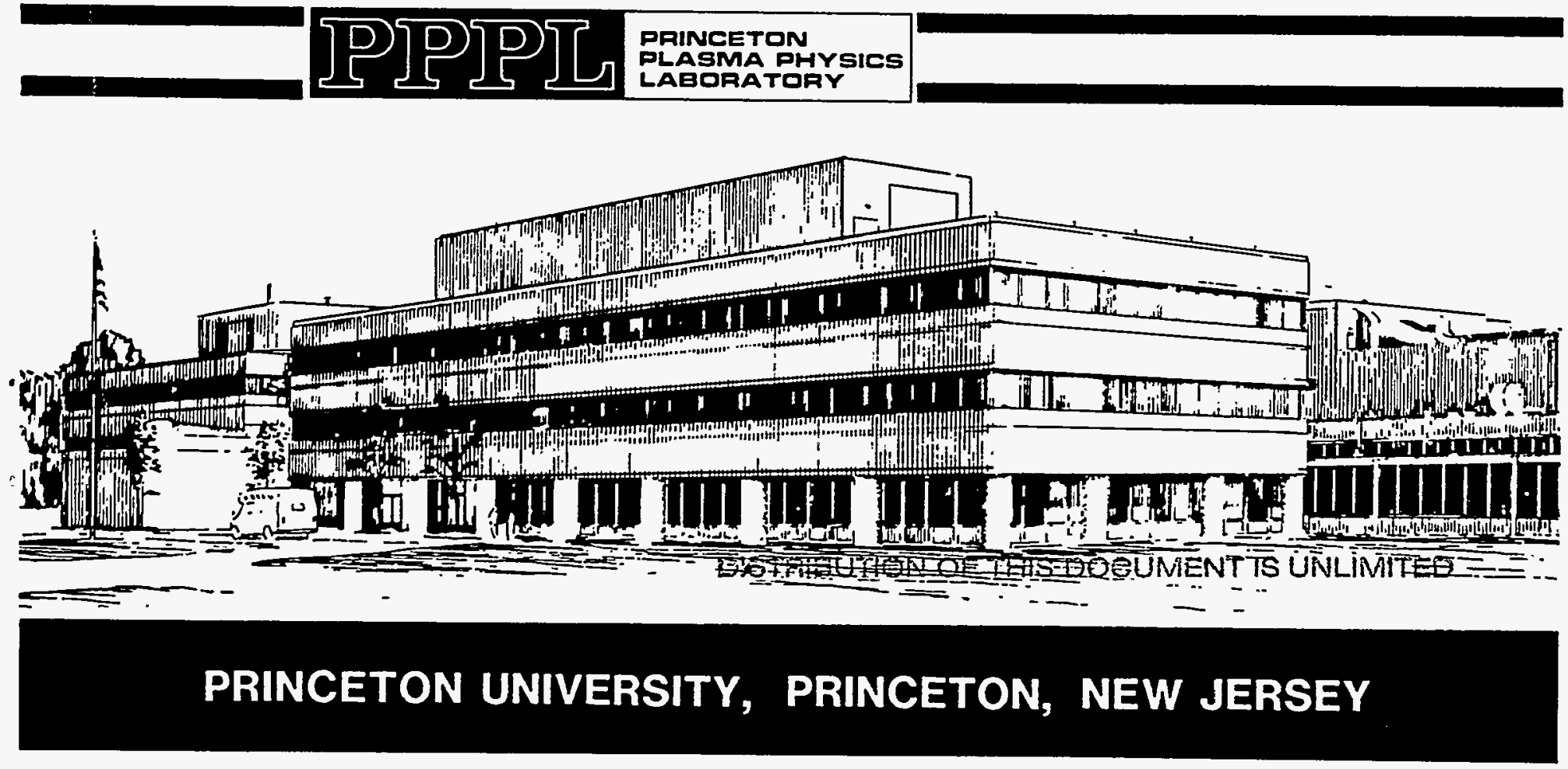

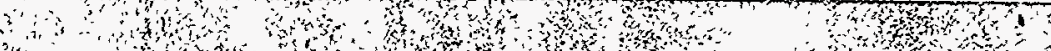




\section{NOTICE}

This report was prepared as an account of work sponsored by an agency of the United States Government. Neither the United States Government nor any agency thereof, nor any of their employees, makes any warranty, express or implied, or assumes any legal liability or responsibility for the accuracy, completeness, or usefulness of any information, apparatus, product, or process disclosed, or represents that its use would not infringe privately owned rights. Reference herein to any specific commercial produce, process, or service by trade name, trademark, manufacturer, or otherwise, does not necessarily constitute or imply its endorsement, recommendation, or favoring by the United States Government or any agency thereof. The views and opinions of authors expressed herein do not necessarily state or reflect those of the United States Government or any agency thereof.

\section{NOTICE}

This report has been reproduced from the best available copy. Available in paper copy and microfiche.

Number of pages in this report: 36

DOE and DOE contractors can obtain copies of this report from:

Office of Scientific and Technical Information

P.O. Box 62

Oak Ridge, TN 37831 ;

(615) $576-8401$.

This report is publicly available from the:

National Technical Information Service

Department of Commerce

5285 Port Royal Road

Springfield, Virginia 22161

(703) $487-4650$ 


\section{DISCLAIMER}

Portions of this document may be illegible in electronic image products. Images are produced from the best available original document. 


\title{
Role of MHD activity in LH-assisted discharges in the PBX-M tokamak
}

\author{
M. Talvard ${ }^{\dagger}$, R. E. Bell, S. Bernabei, S. Kaye, M. Okabayashi, S. Sesnic, \\ S. von Goeler \\ Princeton Plasma Physics Laboratory, Princeton University, P.O. Box 451, Princeton, NJ 08543

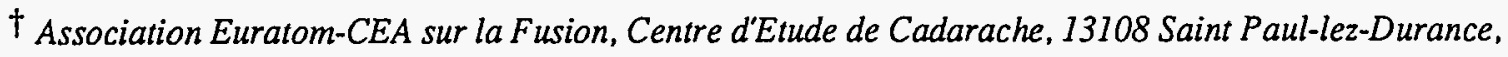 \\ France
}

\begin{abstract}
A data base for the 1993 run period of PBX-M has been documented i) to investigate whether it was possible to forecast the development of MHD instabilities often observed in LH assisted discharges and ii) to detail the origin, the nature and the effects of those instabilities. The deposition radius of the RF current, the plasma internal inductance and the $\mathrm{LH}$ power are used to separate $\mathrm{MHD}$ active and quiescent regimes prior the MHD onset. $1 / 1,2 / 1,3 / 1$ global modes driven by the $\mathrm{m}=2, \mathrm{n}=1$ component are observed in discharges with LHCD. The destabilization is attributed to an increase of the current density gradient within the $q=2$ surface. MHD fluctuations reduce the soft $\mathrm{x}$-ray and hard $\mathrm{x}$-ray intensities mainly around the RF current deposition radius. Minor disruptions with large inversion radii and mode locking are analyzed. A possible precursor to the MHD is evidenced on the hard x-ray horizontal profiles. A resonance between fast trapped electrons and turbulent waves present in the background plasma is proposed to support the observations.

DSTRIBUTION OF THIS DOCUMENT IS UNLIVITTED
\end{abstract}




\section{Introduction}

One of the main purposes of the Plasma Beta Experiment-Modification (PBX-M) tokamak program is to use current and profile control techniques to explore advanced tokamak regimes that could make the next generation of devices more attractive in terms of confinement and stability. In this machine, Lower Hybrid Current Drive (LHCD) with a $2 \mathrm{MW}$ source power at $4.6 \mathrm{GHz}$ has been chosen to shape the current density profile. An earlier report $/ 1 /$ indicated that wave-induced MHD oscillations could affect the confinement of the suprathermal electrons created by the LH waves and thus could degrade both the performance and the control of the discharges.

A key issue is to investigate the role of MHD activity in those discharges so as to optimize the plasma performance. This report is a summary of results collected for the 1993 run period of PBX-M. It deals with a data base of about 200 shots selected between Aug. 25th and Nov. 19th, 1993.

During this experimental campaign, characterized mostly by a $D_{2}$ working gas and bean shaped plasmas, the current drive efficiency has been lower than usual. No global change on the current density profile was observed since the loop voltage drop never exceeded $20 \%$. On the other hand, a clear indication of wave power deposition has been evidenced by the hard $\mathrm{x}$-ray camera. To some extent, we explicit the meaning of wave power deposition in this study but a real understanding of this point will need further analysis of the coupling of the launchers. The conditions were at least settled to assess the role of local perturbations in the current profile and the fast electron population, with concomitant generation or stabilization of MHD activity.

The tools used for this study are described in Sec. II. We report the general trends observed on parameters quantifying the power deposition profile such as the deposition radius, the internal inductance or the spreading of the $\mathrm{RF}$ current deposition just before the onset of the MHD, in Sec. III. The original objective of this study was to investigate whether it is possible to separate MHD active and quiescent discharges. The nature and 
the effects of the MHD are reviewed in Sec. IV. Minor disruptions and mode locking are considered. A possible precursor to the MHD is evidenced on the HXR inverted profiles. A conjecture to explain the observed asymmetries and the relation with MHD is proposed and discussed in Sec.

\section{Investigation tools}

The principal diagnostics used for this study consist of soft $x$-Ray (SXR) diode arrays, a $2 \mathrm{D}$ hard $\mathrm{x}$-Rays (HXR) camera $/ 2 /$ and a magnetic probe array measuring the fluctuations at the plasma edge.

The SXR diagnostic consists of 32 horizontal +32 vertical silicon surface barrier diodes with a spatial resolution of $2.5 \mathrm{~cm}$ in the poloidal direction and $20 \mathrm{~cm}$ in the toroidal direction. Figure 1 shows the plasma flux surfaces of PBX-M and the superimposed SXR lines of sight. The sensitivity of the diodes is in the energy range of 1.2 to $12 \mathrm{keV}$. The signals, in a frequency bandwidth of 0 to $300 \mathrm{kHz}$, could be sampled up to $1 \mathrm{MHz}$.

The HXR diagnostic consists of a pinhole camera looking tangentially in the equatorial plane of the machine and producing 2D images ( $128 \times 128$ pixels) with an equivalent spatial resolution of $3.3 \mathrm{~cm}$ in the plasma. The low-energy cutoff due to the viewing window is $45 \mathrm{keV}$. The detection efficiency decreases gradually for photon energies above $100 \mathrm{keV}$. Sixty four images with a $5 \mathrm{~ms}$ integration time are stored per shot.

The magnetic probe array consists of $15 \mathrm{~B}_{\theta}$ coils ( 10 on the outboard side and 5 on the inboard side) for toroidal mode number identification. Standard data acquisition with sampling rates up to $100 \mathrm{kHz}$ were used for this study.

An IDL(Interactive Data Language) reference plotting program is used for a firststep data analysis. Figure 2 plots plasma current, loop voltage, additional power coupled to the plasma and average line integrated density in unit of $10^{19}$ particles $\mathrm{m}^{-3}$. Also shown 
are the poloidal beta and the internal inductance as calculated by the "SURFAS" magnetostatic code from diamagnetic measurements. The MHD activity signal corresponds to the envelope of the Mirnov oscillations for 8 different frequency bandwidths from 1 to $128 \mathrm{kHz}$. The lower trace corresponds to the envelope of the $1 \mathrm{kHz}$ signal and is used to monitor mode locking. Bursts on this low frequency signal have been identified as due to the sudden slowing down of previously rotating modes. Two SXR signals from the horizontal camera are selected on the bottom left box. The upper trace corresponds to the equatorial line of sight while the diode signal for the lower trace aims outside the $\mathrm{q}=1$ surface in normal conditions. The bottom right box displays two signals deduced from the 2D HXR camera. The upper trace is the ratio of an averaged intensity (over several pixels) at mid radius to an averaged intensity at the center for a central vertical slice of the HXR image. It quantifies the hollowness of the vertical profiles and is $<1$ for peaked profiles. The second signal monitors the presence of either locked modes or runaway electrons. It represents the percentage of pixels in the outer part of the image whose intensity is above a threshold value determined as a function of the averaged intensity of the central image. It particularly reveals bright spots on limiters and/or stabilizing plates located around the plasma.

As we know, runaway electrons are most likely initiated at the plasma center and do perturb the HXR intensities, we took the precaution to keep in the data base only shots having no initial runaway population as measured by the camera prior the LH pulse. A comprehensive study of runaways and their effects, both on current profile and MHD behavior, are crucial in advanced tokamak scenarios but should be treated apart. Moreover, we have only considered in the data base, shots with no additional NBI or IBW power. 


\section{General trends observed before the onset of the MHD}

The total net power coupled to the plasma by the LHCD system is shown in Fig.3 for all the shots selected in the 1993 run period of PBX-M. In this data base, the average line density just before the application of the $\mathrm{LH}$ power is in the range $1-310^{19} \mathrm{~m}^{-3}$, the plasma current ranges between 145 and $250 \mathrm{kA}$ and the toroidal magnetic field between 1.25 and 1.9 T. Except for the last 10 shots dated Nov. $15^{\text {th }}$ and $19^{\text {th }}$ that used $\mathrm{H}_{2}$, the filling gas was $D_{2}$. The plasma is bean shaped in all the cases (see Fig.1).

We report here the more striking trends in the observations. Figure 4 shows the hollowness of the central vertical profile of the HXR image versus the density taken 30 $\mathrm{ms}$ after the application of the $\mathrm{LH}$ power (in most of the cases, this $30 \mathrm{~ms}$ delay is sufficient for the hollowness to reach a stationary value). The largest hollowness is obtained at high densities that also correspond to MHD quiescent discharges (open circles). The closed circles correspond to shots that will develop MHD activity later on.

As previously reported, ${ }^{13 /}$ The HXR images are often characterized by a bright ring that is supposed to localize roughly the LH power deposition. The radius of this bright ring is computed from an inversion of the vertical slice of the image. It is plotted versus the line averaged density in Fig.5. The linear dependence is not so obvious in Fig.5 as in Fig.4, since we observe ring radii of $15 \mathrm{~cm}$ for quite low densities. If we argue that the HXR ring radius is relevant to the physics of the wave absorption and the hollowness is relevant to the diffusion of the fast electrons, we deduce from the two previous figures that the density alone is not the critical parameter in the wave damping process but plays a significant role in the diffusion of fast electrons.

Accessibility of the $\mathrm{LH}$ waves might also play a role. The waves propagate in the plasma only if the wave parallel index $\mathrm{N}_{/ /}=\frac{\mathrm{C}}{\mathrm{v}_{/ /}}$is greater than the plasma accessibility index which is roughly proportional to $\frac{\omega_{c}^{2}}{\omega_{p}^{2}} \approx \frac{B^{2}}{n_{e}}$. We have plotted in Fig. 6 the HXR ring radius as a function of this parameter, for $\mathrm{N}_{/ /}=2.1$ corresponding to $-90^{\circ}$ phasing between two consecutive waveguides of the LH couplers. The linear 
dependence observed indicates that the wave absorption (Landau damping of the wave on the Maxwellian distribution) seems to occur at a radial position determined by the wave accessibility condition. Measurements made for other phasings confirm the same tendency. The consequences of this observation are discussed in Sec. V.1. The main conclusion to be used in the following text is that the HXR bright ring is more representative of the deposition of the RF current than the deposition of the LH power.

From Fig.4, 5 and 6, it appears difficult to separate MHD active (closed circles) and quiescent discharges (open circles). High density discharges associated with large hollowness (high contrast) of the HXR image are stable in all the cases investigated. In addition, discharges are rather unstable when $\mathrm{LH}$ waves are coupled to the plasma core. However, we could not forecast the development of the MHD when the LH waves are coupled off-axis i.e., for HXR ring radii between 10 and $16 \mathrm{~cm}$. The most effective way we found to separate those discharges has been to plot the internal inductance $l_{i}$ (taken in most of the cases $50 \mathrm{~ms}$ after turning on the LH power) as a function of the parameter $\mathrm{P} \frac{\mathrm{B}^{2}}{\mathrm{n}_{\mathrm{e}}}$ where $\mathrm{P}$ is the LH power (Fig.7). The $50 \mathrm{~ms}$ delay has been shortened in cases where MHD appears earlier. It was, however, long enough for the total current profile to respond significantly to the driven current. High power combined with on-axis coupling of the LH waves is most likely MHD unstable. The fact that $l_{i}$ may be a determining parameter confirms the role played by the current profile on MHD stability. Within the error bars in the determination of the internal inductance, it is reasonable to define two separate domains on the figure. The stable domain corresponds to low $l_{i}$ at rather high $\mathrm{P} \frac{\mathrm{B}^{2}}{\mathrm{n}_{\mathrm{e}}}$ or high $\mathrm{l}_{\mathrm{i}}$ if $\mathrm{P} \frac{\mathrm{B}^{2}}{\mathrm{n}_{\mathrm{e}}}$ remains small. If LHCD had no effect on the current profile, one would expect an horizontal straight line separating the two domains. The separation curve is then attributed to the local contribution of the LHCD to the total current. The de stabilization mechanism seems to be related to an increase of the local gradient of the current near the resonant surface $q=2$ (as inferred later on). This representation then combined local effects associated with the RF current deposition $\frac{\mathrm{B}^{2}}{\mathrm{n}_{\mathrm{e}}}$ and the ohmic target plasma $\mathrm{l}_{\mathrm{i}}$. Indeed, low $\mathrm{l}_{\mathrm{i}} \mathrm{MHD}$ unstable discharges correspond to high power and offaxis RF current deposition. If the tendency were confirmed during further experiments, 
the frontier curve could be used to qualify the destabilizing effect of LHCD. For example, at given deposition radius, the figure indicates the maximum low hybrid power allowed to remain stable.

\section{Analysis of MHD active discharges}

\section{IV.1 Nature of the MHD instabilities}

Several typical shots have been analysed in detail to understand the observed MHD oscillations. Figure 8 shows the signals of the 21 innermost lines of sight of the SXR horizontal camera of shot \# 306066. The parameters of the plasma are $P_{L H}=165$ $\mathrm{kW}, \mathrm{I}_{\mathrm{p}}=213 \mathrm{kA}$ and $\left\langle\mathrm{n}_{\mathrm{e}}\right\rangle=2.10^{19} \mathrm{~m}^{-3}$. LH power is turned on and the net power kept constant from 400 to $600 \mathrm{~ms}$. The sawtooth inversion radius is initially stable and rather small (around $6 \mathrm{~cm}$ ). The LH power suppresses the sawteeth even though there is no indication of a shrinking of the inversion surface. The onset of a $1 / 1,2 / 1,3 / 1$ rotating mode is observed $22 \mathrm{~ms}$ after turning on the LH power. The three components are coupled (same frequency) but the normalized fluctuation amplitude is maximum for $2 / 1$ and $3 / 1$, which turns out to be the driving modes. After saturation of the mode, we observe a minor disruption (around $450 \mathrm{~ms}$ and $480 \mathrm{~ms}$ ) with an inversion radius of 20 $\mathrm{cm}$. This internal disruption does not involve the centre of the plasma (and particularly not the $\mathrm{q}=1$ surface) but is more reminiscent of an ELM except that ELM's are usually localized more towards the edge (with $m=5-10, n=1$ ). The minor disruption associated with the collapse of the $2 / 1,3 / 1$ components, triggers a very fast growth of the preexisting 1/1 component (visible on Fig. 8 from 452 to $460 \mathrm{~ms}$ and from 482 to $490 \mathrm{~ms}$ ). The normalized fluctuation amplitude of this $m=1$ component reaches 3 times the amplitude of the $\mathrm{m}=2$ and $\mathrm{m}=3$ components while it was 5 times weaker before the collapse (Fig.9). The rotation frequency also increased from $3 \mathrm{kHz}$ before to $5 \mathrm{kHz}$ just after the disruption. This seems to be experimental evidence for a coupling of poloidal magnetic energy from the edge to the plasma centre. A discussion about this original 
disruption is given in Sec. V.2. This situation is not stationary, however, since we observe a damping of the $\mathrm{m}=1$ mode within $7 \mathrm{~ms}$. Then, the $2 / 1$ and $3 / 1$ components are growing again and a new cycle starts. Sometimes the saturation of the $2 / 1$ and $3 / 1$ modes leads to a mode locking occuring before the minor disruption, as for example in shot \#310365 visible on Fig 2. Notice that SXR intensities are rather unaffected by mode locking.

The amplitudes of the SXR fluctuations normalized to their DC level for the $1 / 1$, $2 / 1$ and $3 / 1$ modes are plotted versus the ring radius on Fig.10a. The $m=2$ and $m=3$ components are more destabilized at deposition radii closer to the $\mathrm{q}=2$ surface, which is consistent with a steepening of the current density gradient inside this resonant surface. As expected from Fig.6, the same behavior is observed when plotting the fluctuation amplitudes as a function of the accessibility parameter (Fig.10b). Finally, the $m=1,2,3$ components of the SXR fluctuations are also represented in Fig. 11 versus plasma internal inductance. The tendency is compatible with Fig.7 since low li discharges are destabilized by the local action of the LH power. These discharges indeed correspond to off-axis RF current deposition. For on-axis wave coupling and low LH power (high li on Fig.11), the fluctuation amplitudes are naturally weaker.

\section{IV.2 Effects of the MHD instabilities}

The 1/1, 2/1, 3/1 global mode induces SXR intensity losses from $10 \%$ for central integrated lines of sight to $40 \%$ near the edge (Fig.12). After Abel inversion, the maximum relative losses should be located between the $q=1$ and the $q=2$ surfaces, since the Motional Stark Effect (MSE) diagnostic indicated that for similar discharges with a $\mathrm{q}=1$ surface around $7 \mathrm{~cm}$, the $\mathrm{q}=2$ and $\mathrm{q}=3$ surfaces were at 20 and $24 \mathrm{~cm}$, respectively.

Since minor disruptions do affect the HXR intensity through density and loop voltage perturbations, we took care measuring the HXR amplitudes before such events. Global magnetic perturbations such as those observed in shot \#306066 reduce the HXR intensity by $20 \%$ for most of the lines of sight and $10 \%$ for the central ones. Again, the maximum losses are within a radius of $20 \mathrm{~cm}$, which is consistent with SXR 
measurements, although losses seem lower by a factor 2 for high energetic electrons.

MHD reduces slightly the HXR profile hollowness. The reduction hardly exceeds $20 \%$. Indeed, the major increase of the peakedness of the HXR image usually observed during MHD active discharges is the effect of the associated minor disruptions. It appeared difficult to quantify the loss of hollowness (attributed to an increased diffusion of fast electrons), as a function of the parameters relevant to profile control. No particular dependence was found on the initial density, the accessibility parameter $P \frac{B^{2}}{n_{e}}$, the plasma internal inductance, the $q$ factor at the edge nor the parallel index of refraction of the LH launched waves. To fix the ideas, we give an example of the relative losses as a function of the HXR ring radius on Fig.13a. No specific dependence is found between the enhanced diffusion of fast electrons and their deposition radius.

The HXR ring radius is also reduced by the MHD activity. The reduction rate can be as large as $100 \%$ particularly at low density (Fig.13b). However, in view of Fig. 5, this also corresponds to small ring radii which confirms the small effect (few centimeters) of the global MHD on the deposition radius of fast electrons.

Hot spots appear often on the HXR images as soon as global MHD develops. These generally do not induce a catastrophic end of the discharge, but could be invoked in the minor disruption mechanism since MHD active shots with no hot spot nor minor disruption have been obtained (for example \#307293). Mode locking is a particular evolution of a growing magnetic activity. HXR intensities do not behave differently in that case (see again \#310365 on Fig.2 for example). HXR profile hollowness is rather unaffected in this example (except after the minor disruption at $410 \mathrm{~ms}$ ). In other words, whether an island chain rotates or not (in the range $1-5 \mathrm{kHz}$ ) does not affect very much the behavior of energetic electrons.

\section{IV.3 Evidence for a precursor of the MHD}

In the horizontal mid-plane, a direct Abel inversion of the HXR integrated image can be achieved. ${ }^{14 /}$ A typical inverted profile calculated for a standard "hollow" discharge is shown on Fig.14a. The HXR amplitude is expected to be naturally larger on 
the low major radius side of the magnetic surface associated with the location of the power deposition, because toroidicity induces a higher density of flux tubes in that region. There is an interesting trend observed in the HXR inverted profiles prior to the onset of the MHD for all the hollow-type discharges investigated. An asymmetry, such as the one visible on Fig.14b, appears on at least one and more often on several successive inverted profiles before the discharges develop MHD. This corresponds in all the cases (7 available in the data base) to LH pulses starting with hollow images, characterized by a bright ring that suddenly becomes rather uniform, with an average intensity with respect to the previous images. The inversion code then deduces a profile with an amplitude naturally larger for large radius. The good correlation with the MHD activity seems to exclude any instrumental problem. We discuss the origin of this asymmetry and the possible consequences on MHD in Sec. V.3. Following this, the developing MHD tends to smooth the asymmetry (see profile 11 on Fig.14b). The losses observed on the inverted horizontal profile are consistent with those reported previously on the vertical profiles. Notice that MHD does not systematically follow asymmetric profiles. We analyzed shots with up to $25 \mathrm{~ms}$ delay ( 5 images) between the last asymmetric profile and the onset of the MHD. Finally, discharges with peaked power deposition profiles, which we know to be most likely MHD unstable, have not revealed any asymmetry. Since asymmetries are hardly detectable on peaked inverted profiles, this does not prove the absence of asymmetry in such cases.

\section{Discussion}

\section{V.1 Absorption radius of the LH power}

Lower hybrid power is expected to be absorbed in a plasma by Landau damping of the launched waves on electrons moving at velocities close to the wave phase velocity. Since the parallel index $N_{/ /}$of the launched waves is typically around 2 , the corresponding resonant energy is $\approx 70 \mathrm{keV}$, which involves very few electrons in a $1 \mathrm{keV}$ 
Maxwellian distribution. This famous "spectral gap" is generally supposed to be bridged by a $N_{/ /}$upshift (up to 5 at least) of hybrid waves during their propagation in the torus. Because of the dispersion relation of the waves, it is possible to figure out what is the minimum $\mathrm{N}_{/ /}$needed for the wave to propagate at a given radius $\mathrm{R}$ in the plasma. This value is typically between 1 and 2.8 in PBX-M and is referred to as the accessibility condition. The fact that in view of Fig.6, the wave damps at a radius related to the accessibility parameter seems to indicate that the $\mathrm{N}_{/ /}$did not change much before absorption. Changing the phasing between two consecutive waveguides of the $\mathrm{LH}$ coupler is a way to vary the $\mathrm{N}_{/ /}$of the launched waves between 1.7 to 4.5 typically. Previous work $/ 5 /$ indicated a qualitative and quantitative agreement between the power deposition radius during phase scans and the classical accessibility. If the HXR bright ring were really related to the power absorption radius, this would imply that there is no $\mathrm{N}_{/ /}$upshift for the wave to be absorbed in PBX-M. Another possibility is that the bright ring corresponds to the emission of a few energetic electrons only (which could also correspond to most of the RF current deposition since the current drive efficiency is higher for high energy electrons). The absorption of the rest of the power on the plasma bulk would then occur elsewhere, after $\mathrm{N}_{/ /}$upshift but without any measurable signature on the HXR images.

\section{V.2 Minor disruptions with large inversion radii}

Minor disruptions with inversion radii close to the $\mathrm{q}=2$ surface have been frequently observed during the 1993 period of run of PBX-M. The radius of the HXR bright ring $(<16 \mathrm{~cm})$ is consistent with a RF current driven within the $\mathrm{q}=2$ surface $(\approx 20 \mathrm{~cm}$ ). The destabilized $2 / 1$ mode then drives the $3 / 1$ and $1 / 1$ components by toroidal coupling since the frequencies are the same for the three modes. According to this picture, the minor disruption can be explained as a reconnection between the $q=2$ and $q=3$ perturbated surfaces. The disruption causes a redistribution of the current profile that destabilizes the $\mathrm{m}=1$ component. In other words, the amount of poloidal magnetic energy needed to destabilize the plasma edge is now available at the centre. It is 
interesting to observe the frequency of the modes during the collapse. As the oscillations on the SXR signals can be attributed to the rotation in the poloidal plane of magnetic islands with the angular velocity $\frac{\omega}{\mathrm{k}}=\frac{\mathrm{r} \omega}{\mathrm{m}}$ around the magnetic axis, we remark that the observed frequencies ( $3 \mathrm{kHz}$ before and $5 \mathrm{kHz}$ after the crash) and the direction of motion match the diamagnetic motion of the electrons since for $\mathrm{m}=2, \mathrm{r}=0.15 \mathrm{~m}$ and using $T_{e}=T_{e 0}\left(1-\left(\frac{T}{a}\right)^{2}\right)^{2}$ with $T_{e 0}=1 \mathrm{keV}$, we find $\omega_{e}{ }^{*}=2.6 \mathrm{kHz}$ and for $\mathrm{m}=1$, $\mathrm{r}=0.07 \mathrm{~m}, \omega_{\mathrm{e}}{ }^{*}=4.5 \mathrm{kHz}$. As far as the local plasma velocity can be expressed, in cases of no application of external momentum, as the sum of the electric drift velocity $v_{E}=\frac{1}{B} \frac{d U}{d r}$ (where $U$ is the electric potential in the plasma) and a diamagnetic velocity $\mathrm{v}^{*}$, we deduce that electronic diamagnetism stirs the islands and that the electric contribution is weak in those experiments.

\section{V.3 Asymmetry of the HXR inverted profiles}

Regarding the asymmetry of the HXR inverted profiles observed before the onset of the MHD, we tried to review any mechanism able to account for an increase of the HXR intensity in the low field side of the torus. A first examination of the HX raw data showed that this was not due to the appearance of localized hot spots since the intensity is rather uniform across the entire 2D image. The event has then been compared with SXR vertical measurements which did not show any similar asymmetry. We conclude that the event is not to be attributed to impurity influxes nor deviations on the low energetic part of the particle distribution function. Then, we investigated mechanisms able to interact with particles in the LHCD energy range. A first candidate is the Parail Pogutse instability $/ 6 /$ that could develop since a tail in the parallel component of the velocity distribution has been sustained by the LH waves. The strong relaxation of the parallel to the perpendicular energy of the particles could suddenly increase the number and the energy of trapped particles which are located in the low field side of the machine and then might generate an asymmetry in the HXR images. However, the persistence of the asymmetry observed sometimes during 6 consecutive images ( $30 \mathrm{~ms}$ ) is hardly compatible with the kinetic character of the instability (supposed to occur within tens of 
$\mu \mathrm{s})$. Moreover, a strong signature on ECE measurements should be observed during those bursts which, within the few measurements available at that time, was not the case. This interpretation needs to be supported during further experiments.

Another possibility is to consider trapped particle instabilities expected to occur in LH assisted plasmas. We are mostly interested in collisionless phenomena since high energetic electrons have been invoked. We need first to find a resonance between any pre-existing perturbation at given frequency $\omega$ and the motion of the high energetic trapped electrons in the plasma, namely :

$$
\omega=\left\langle\omega_{\mathrm{de}}\right\rangle+\mathrm{p} \omega_{\mathrm{be}}
$$

where $\left\langle\omega_{\mathrm{de}}\right\rangle=\frac{\mathrm{g} \mathrm{T}_{\mathrm{e}}}{\mathrm{eBRr}}$ is the precession frequency associated with the slow toroidal drift of the banana orbits and $\omega_{\mathrm{be}}=\frac{1}{\mathrm{qR}} \sqrt{\frac{\mathrm{r}}{2 \mathrm{R}} \frac{\mathrm{T}_{\mathrm{e}}}{\mathrm{m}_{\mathrm{e}}}}$, the bounce frequency of the trapped electrons with $\mathrm{p}=0,1$ mainly. In these expressions, $\mathrm{q}$ is the safety factor taken at minor radius $r$ corresponding to the HXR bright ring, $e$ and $m_{e}$ are the electron charge and mass respectively. Then, we review some possible microinstabilities that could play the role of the background perturbation, use their dispersion relation and replace $\omega$ in the resonance condition in order to find out a resonant energy for electrons in the LH energy range (up to $200 \mathrm{keV}$ on PBX-M). The damping of this microinstability on a small population of energetic trapped electrons might indeed account for the HXR asymmetry. Electron drift waves are first considered. They are usually characterized by a transverse wave number $k_{y}$ of the order of the inverse ion Larmor radius, $k_{y} \rho_{i} \approx 1$, namely $k_{y} \approx 10 \mathrm{~cm}^{-1}$ in $\mathrm{PBX}-\mathrm{M}$, and a dispersion relation $\omega \approx \omega_{\mathrm{e}}{ }^{*}$ where $\omega_{\mathrm{e}}{ }^{*}=k_{\mathrm{y}} \frac{\mathrm{T}_{\mathrm{e}}}{\mathrm{eBL}_{\mathrm{n}}}$ is the electron diamagnetic frequency, if $L_{n}$ is the density gradient length. No significant resonance can be found for $\mathrm{p}=0$. However, for $\mathrm{p}=1$ and $\mathrm{k}_{\mathrm{y}}$ in the range [1-10] $\mathrm{cm}^{-1},[1-20] \mathrm{keV}$ electrons are resonant with a corresponding [100-800] $\mathrm{kHz}$ frequency spectrum . For $\mathrm{p}=$ 2 , resonances are found for [2-90] $\mathrm{keV}$ electrons and [700-3000] $\mathrm{kHz}$ frequencies. Ion Temperature Gradient (ITG) modes are also investigated. The dispersion relation $17 / \mathrm{can}$ be written $\omega=k_{y}\left\{\left(\frac{B_{\theta}}{B_{\varphi}}\right)^{2} \frac{T_{e} T_{i}}{e^{2} m_{i} B_{n}}\right\}^{1 / 3}$ which produces a resonance with $k_{y}=1-2 \mathrm{~cm}^{-1}$ for [5-300] keV electrons and [300-3000] kHz frequencies $(p=1)$. However, the strong $\mathrm{k}_{\mathrm{y}}$ dependence in the resonance condition $\left(k_{y}{ }^{6}\right)$ considerably reduces the $k_{y}$ extent of the 
resonant background turbulence. This seems too restrictive to account for a good coupling between the turbulent waves and the trapped electron population. Finally, it is found that magnetic turbulence such as microtearing modes with typical frequencies of [.5-1] $\mathrm{MHz}$ could also resonate with [10-50] $\mathrm{keV}$ electrons $(\mathrm{p}=1)$.

Clearly, this is a very preliminary picture that has to be confirmed and quantified in future experiments. Turbulence measurements (particularly density fluctuations with Langmuir probes and reflectometry at the plasma edge) were unfortunately not available for our limited data base. This scenario, if correct, would result in a reduction of the fluctuation level in LH-assisted discharges before the onset of the MHD. Notice that such a behavior has probably already been seen on PLT. /8/ Detailed diagnostis of the turbulent spectrum with the use of the trapped particle resonance might help to discriminate between the various background microinstabilities. For example, ITG modes, when resonating, need a $\mathrm{k}_{\mathrm{y}}$ wave number in the range [1-2] $\mathrm{cm}^{-1}$ exclusively. This should be documented in future experiments.

Relation between HXR asymmetry and MHD could be understood as follows : as the energy of the turbulent waves is damped on the fast trapped electrons initiated by the LH waves, the energy of this population increases resulting in the asymmetry observed in the HXR horizontal profiles. The particles that gained energy from the turbulence should help in turn the coupling of the LH waves. The current drive efficiency is thus expected to increase. Indeed, we observed an increase of the total plasma current and a subsequent decrease in the loop voltage for the time period associated with the asymmetric profiles (the loop voltage was constant or slightly increasing before the first asymmetric profile and is increasing during the MHD phase). The RF driven current is then boosted resulting in an easier destabilization of the $\mathrm{m}=2$ mode. This synergy effect between LH waves and the background turbulence is of course highly speculative in the present experiments. For instance, we still do not understand why the resonance condition seems sometimes fulfilled and sometimes not. Incidentally, it is interesting to wonder whether this coupling between microinstabilities and fast trapped electrons could help to fill the famous $\mathrm{LH}$ 
spectral gap in tokamaks. These points could be investigated in details during the next PBX-M experimental session.

\section{Conclusions}

A data base for the 1993 period of run of PBX-M has been documented to investigate first, whether it was possible to forecast the development of the MHD instabilities from specific trends associated with Lower Hybrid Current Drive and second, to explain the origin, the nature and the effects of this MHD. Only bean shaped plasmas with $D_{2}$ working gas and without neutral beams have been studied.

As specific trends, it appears first that the radius of the bright ring observed on the 2D HXR images is related to the accessibility of the LH waves. As a consequence discussed in Sec. V.1, the bright ring cannot any longer represent the location of the power deposition (except if one supports the invariance of $\mathrm{N}_{/ /}$during the power absorption). Instead, the bright ring, involving high energetic electrons, is probably more relevant of the deposition of the RF current. The contrast of the HXR bright ring (profile hollowness), then related to the diffusion of these high energetic electrons and thus the spreading of the RF current, is roughly proportional to the plasma density.

We could not forecast the development of the MHD instabilities from the simple analysis of the deposition radius of the RF current. Discharges with central RF current deposition are, however, always unstable (within the framework of the data base).

Conversely, high density plasmas $\left(<n_{e}>>2.710^{19} \mathrm{~m}^{-3}\right)$ with subsequent low spreading of the RF current, remain stable. The MHD onset seems related to the plasma internal inductance which is, in turn, mostly determined by the ohmic part of the current. A possible separation between stable and unstable regions is proposed in Fig.7 which combines global current shape (li), local RF current deposition $\left(\frac{B^{2}}{n_{e}}\right)$ and $L H$ power $P$. 
However, uncertainties in the determination of li could affect the boundary line. Further experiments are needed to document this observation.

Lower hybrid-induced instabilities are identified as global modes with poloidal number $\mathrm{m}=2$ and $\mathrm{m}=3$ and toroidal number $\mathrm{n}=1$. The amplitude of MHD fluctuations are larger for RF current deposition closer to the $\mathrm{q}=2$ surface and are inconsistently lower $\mathrm{l}_{\mathrm{i}}$ discharges. For RF current driven on-axis or for low $\mathrm{LH}$ power (higher $\mathrm{l}_{\mathrm{i}}$ discharges), the nature of the MHD is still $\mathrm{m}=2$ mainly, though amplitudes are weaker (Fig.11).

MHD instabilities are responsible for SXR intensity losses of about 50\% mainly localized around $10 \mathrm{~cm}$, between the $\mathrm{q}=1$ and the $\mathrm{q}=2$ surfaces. This is consistent with HXR measurements except that intensity losses are smaller by a factor 2 for energetic electrons. In particular, the spreading of the RF current (attributed to an enhanced diffusion of fast electrons) is less than $25 \%$ in all the cases. On the other hand, global modes reduce the deposition radius of the RF current only by a few centimeters. Hot spots appear in the periphery of the plasma as soon as MHD grows.

Minor disruptions with an inversion radius at the $q=2$ surface are observed during LHCD. Those disruptions probably involve a reconnection between the $q=2$ and the $q=3$ surfaces but are also associated with the presence of hot spots visible on the HXR images, especially in the cases where there is no evidence for rotating islands. Coupling of the poloidal energy from the edge $(q=2,3)$ towards the centre $(q=1)$ is evidenced. Disruptions are also responsible for the peaking of the HXR emissivity profiles often observed in MHD active discharges.

Mode locking has little effect on both SXR and HXR intensities. The dynamics of the fast electrons is not particularly affected by mode locking.

Finally, asymmetric HXR inverted profiles are evidenced in the horizontal plane prior to the onset of the MHD for initially hollow discharges. This precursor event is present in the seven cases considered in the data base. The asymmetry is interpreted as an energy increase of high energetic trapped electrons initiated by the LH waves. A resonance between the population of fast trapped electrons and turbulent waves present in 
the background plasma is proposed to support their energy increase. Increased LHCD efficiency then boosts the RF driven current which can destabilize MHD. 


\section{Acknowledgements}

One of the authors (M. Talvard) would like to thank the PBX-team and technical crew for its hospitality during my stay at Princeton. This work was supported by the US Department of Energy Contract No. DE-AC02-766-CHO-3073.

\section{REFERENCES}

I1 R.E. Bell et al., Proceedings of the Conf. on Radio-Frequency Power in Plasmas, Boston, MA, (April 1993), AIP 289, 202-209 (New York, NY, 1993)

12/ S.von Goeler et al., PPPL Report 2909, (1993).

13/ S. Bernabei and the PBX-M group, in 35th Annual Meeting of the Division of Pasma Physics of the APS, St Louis, MO, (1993), Bull. APS, $\underline{38}, 2091$.

14/ Ronald E. Bell to be published in Rev. Sci. Instr.

15/ S.von Goeler et al., in 35th Annual Meeting of the Division of

Plasma Physics of the APS, St Louis, MO, (1993), Bull. APS, 38 , 2092.

16/ V.V. Parail, O.P. Pogutse, Nucl. Fusion 18, 303, (1978).

171 S.C. Cowley et al., Phys. Fluids B 3, 2767, (1991).

18/ T.K. Chu et al., Nucl. Fusion 26, 666, (1986). 


\section{FIGURE CAPTIONS}

Fig.1 Poloidal view of PBX-M and SXR lines of sight.

Fig.2 Typical example of output data available after every shot.

Fig.3 Lower Hybrid net power coupled to the plasma for the 1993 data base.

Fig.4 Hollowness of a central vertical slice in the 2D HXR image versus plasma density for MHD active and quiescent discharges.

Fig.5 Radius of the HXR bright ring versus plasma density for MHD active and quiescent discharges.

Fig.6 Radius of the HXR bright ring versus the accessibility parameter.

Fig.7 Plasma internal inductance for MHD active and quiescent discharges.

Fig.8 Time signal of the 19 innermost channels of the horizontal SXR camera for a typical discharge with MHD.

Fig.9 (a) Amplitude of the SXR fluctuations as a function of the vertical $\mathrm{Z}$ coordinate before the minor disruption visible on Fig.8.

(b) Amplitude of the SXR fluctuations as a function of the vertical Z coordinate after the minor disruption visible on Fig.8.

Fig.10 (a) SXR normalized fluctuations of $1 / 1,2 / 1$ and $3 / 1$ components versus HXR ring radius.

(b) SXR normalized fluctuations of $1 / 1,2 / 1$ and $3 / 1$ components versus the accessibility parameter.

Fig.11 SXR normalized fluctuations of $1 / 1,2 / 1$ and $3 / 1$ components versus plasma internal inductance.

Fig.12 SXR intensity losses due to the MHD activity visible on Fig.8.

Fig.13 (a) Relative hollowness loss versus HXR ring radius.

(b) Relative reduction of the HXR ring radius versus plasma density.

Fig.14 (a) Result of the Abel inversion of the horizontal HXR profiles for a typical hollow-type discharge.

(b) Asymmetric HXR inverted profiles obtained before the onset of the MHD (4)\&(5) and smoothing effect of the MHD (11). 


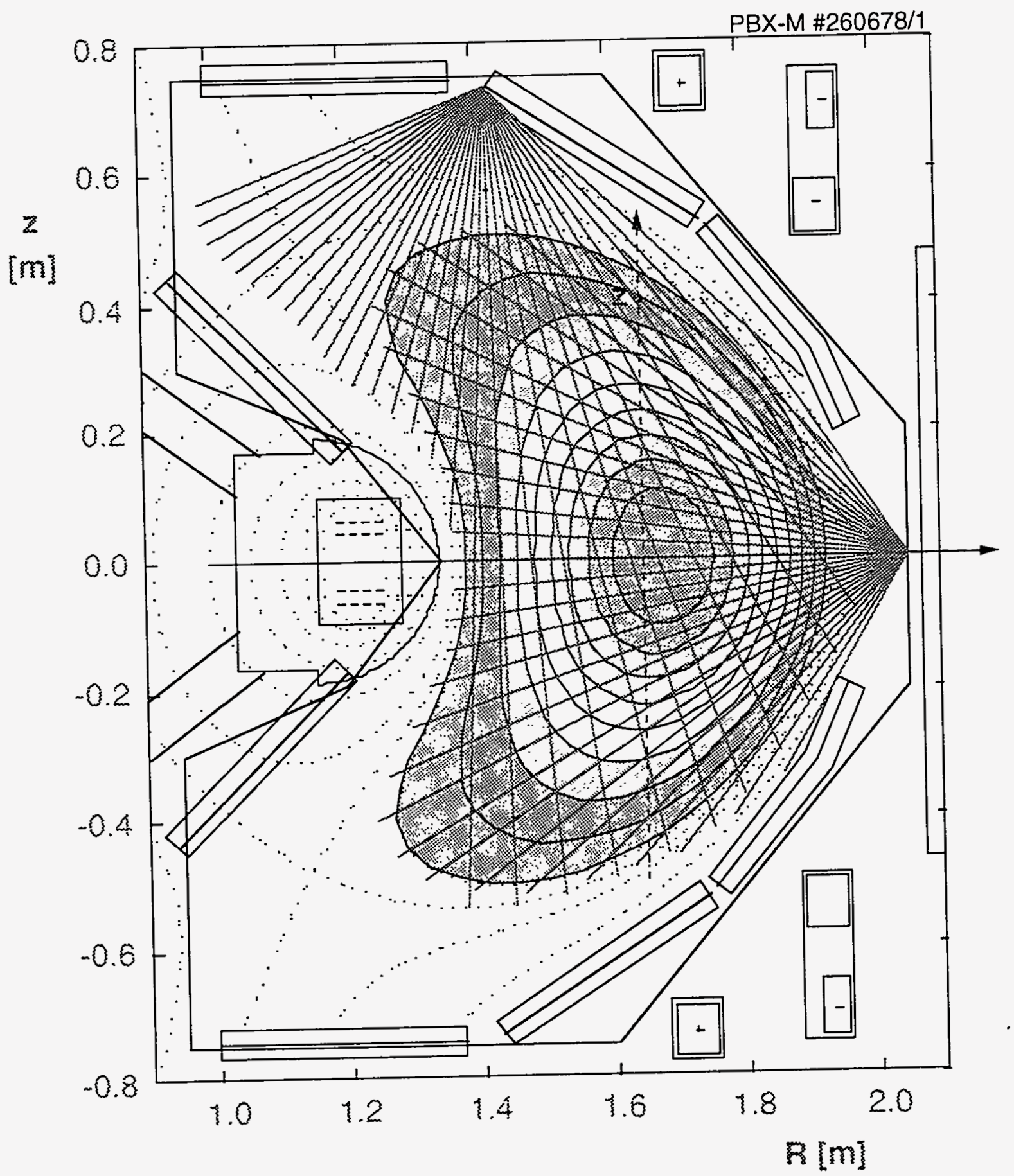

Fig.1 
Shot \# 310365

Bean Shape
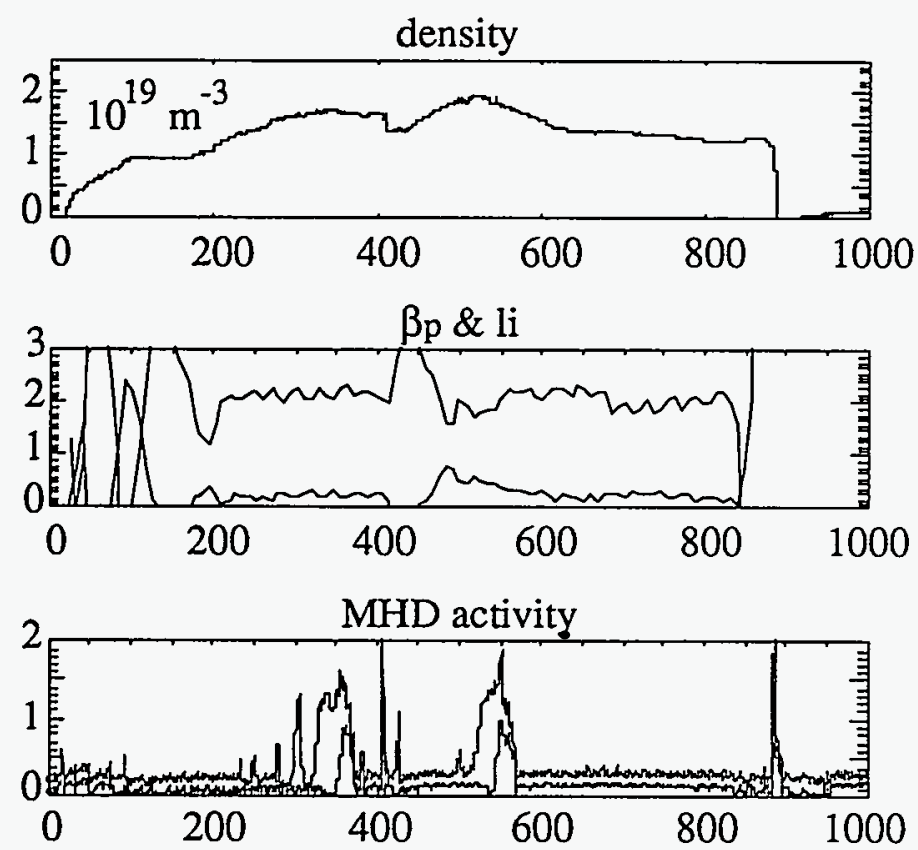

SXR horiz. views 0 \& 7

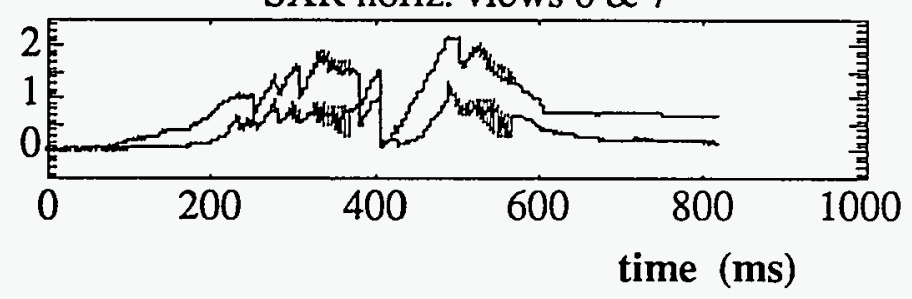

Plasma current

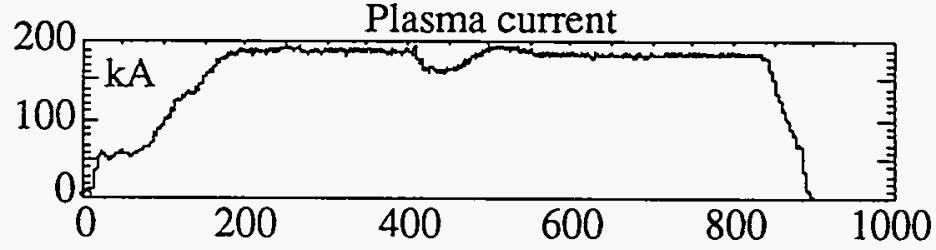

Loop voltage

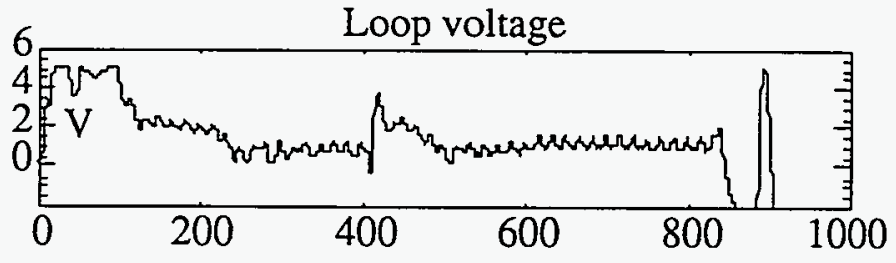

NBI \& IBW

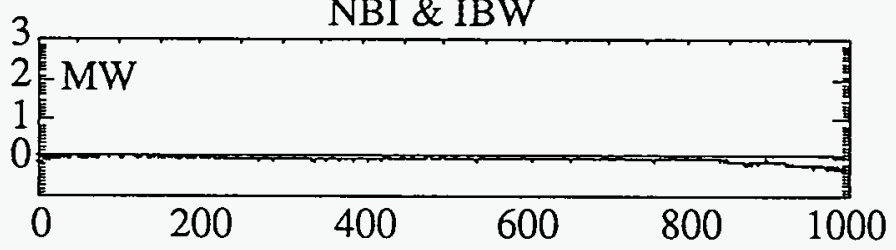

LH

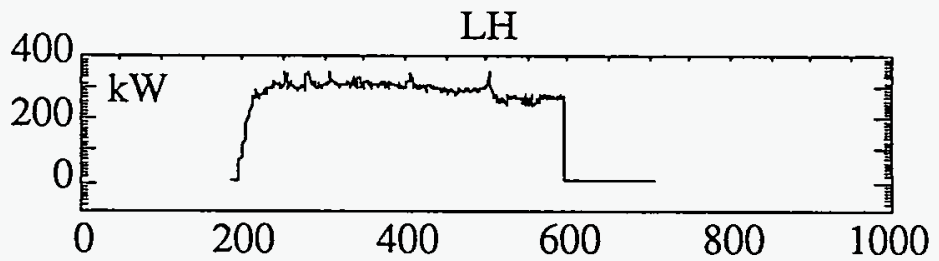

HXR vertical hollowness \& Hot spots (\%)

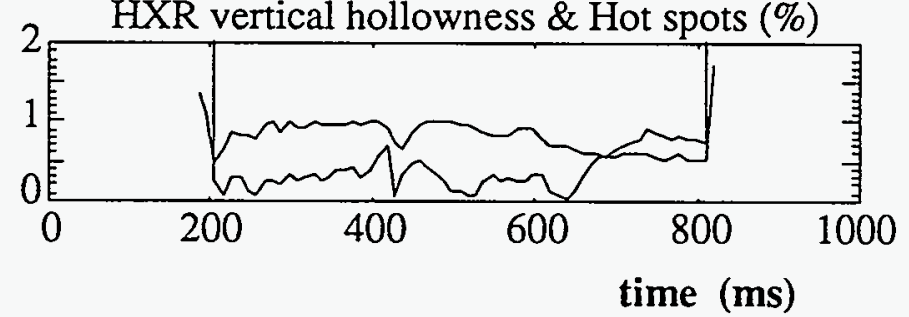

Fig.2 


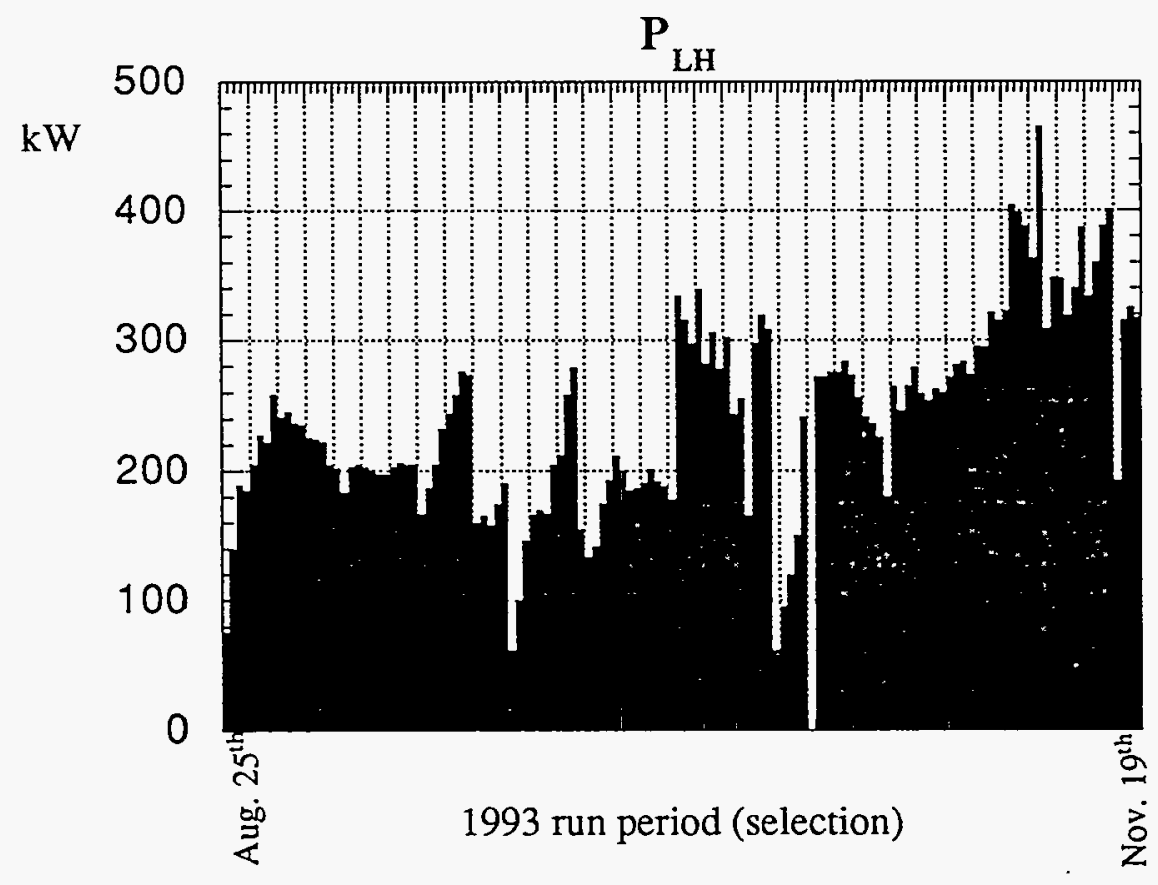

Fig.3 


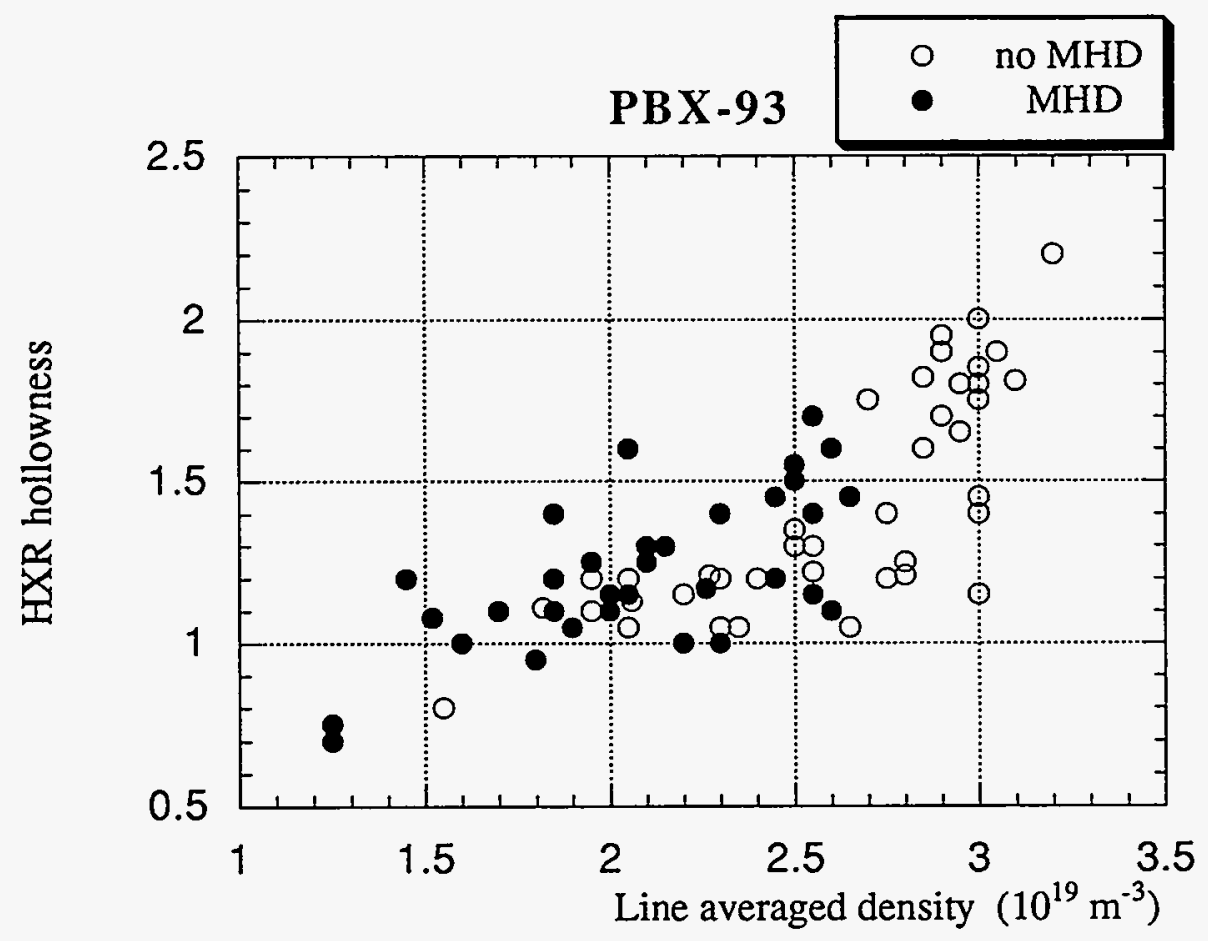

Fig.4 


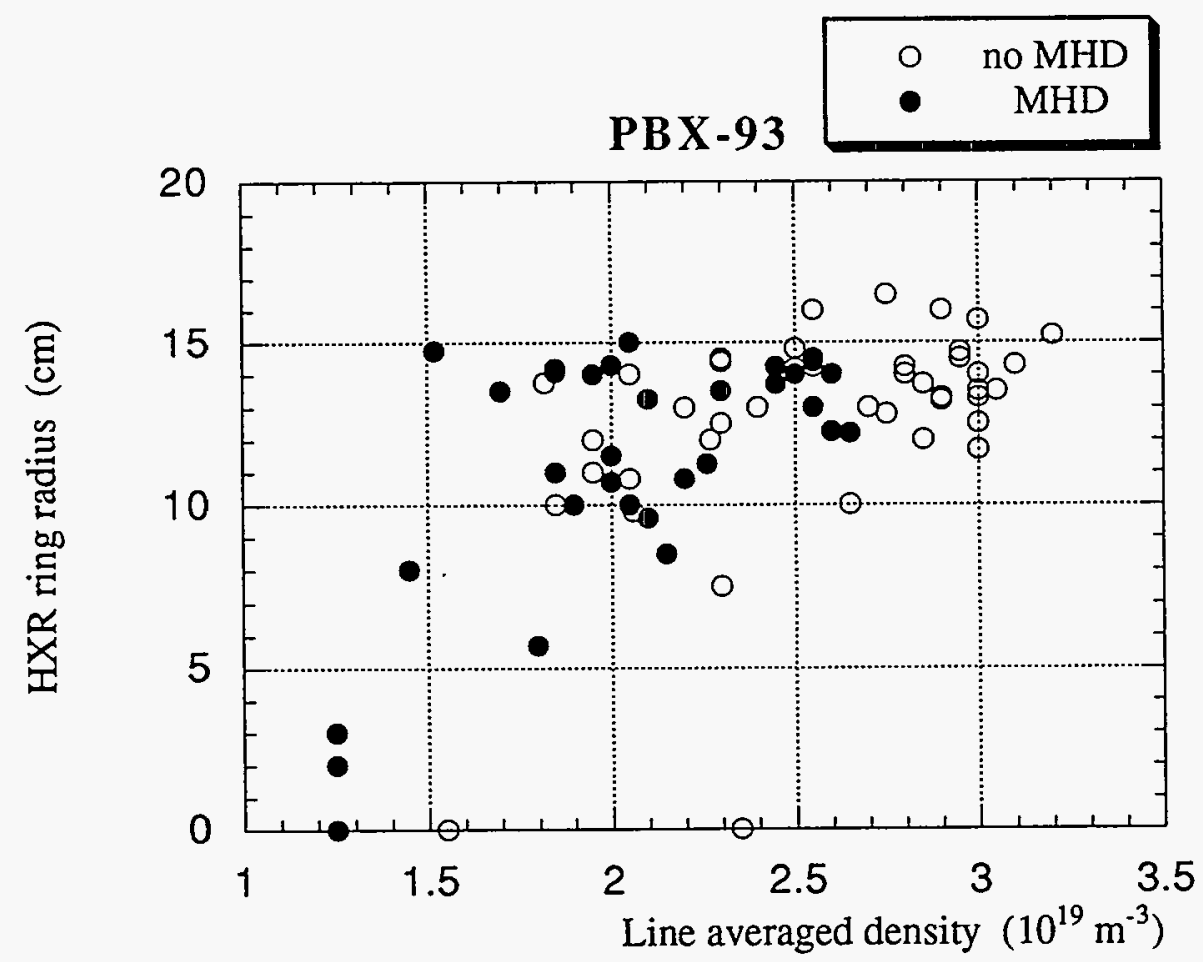

Fig.5 


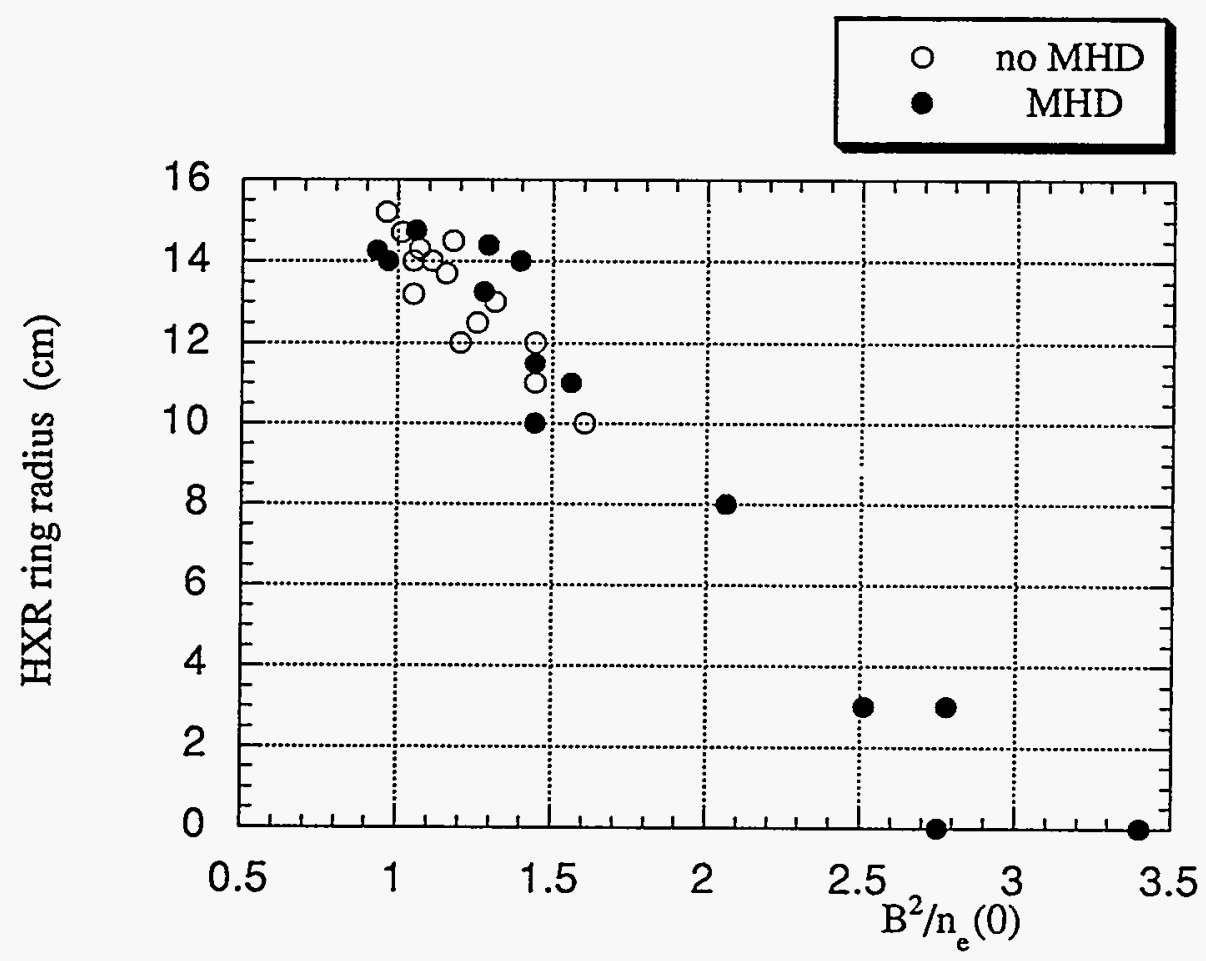

Fig. 6 


\section{- LI
LImhd}

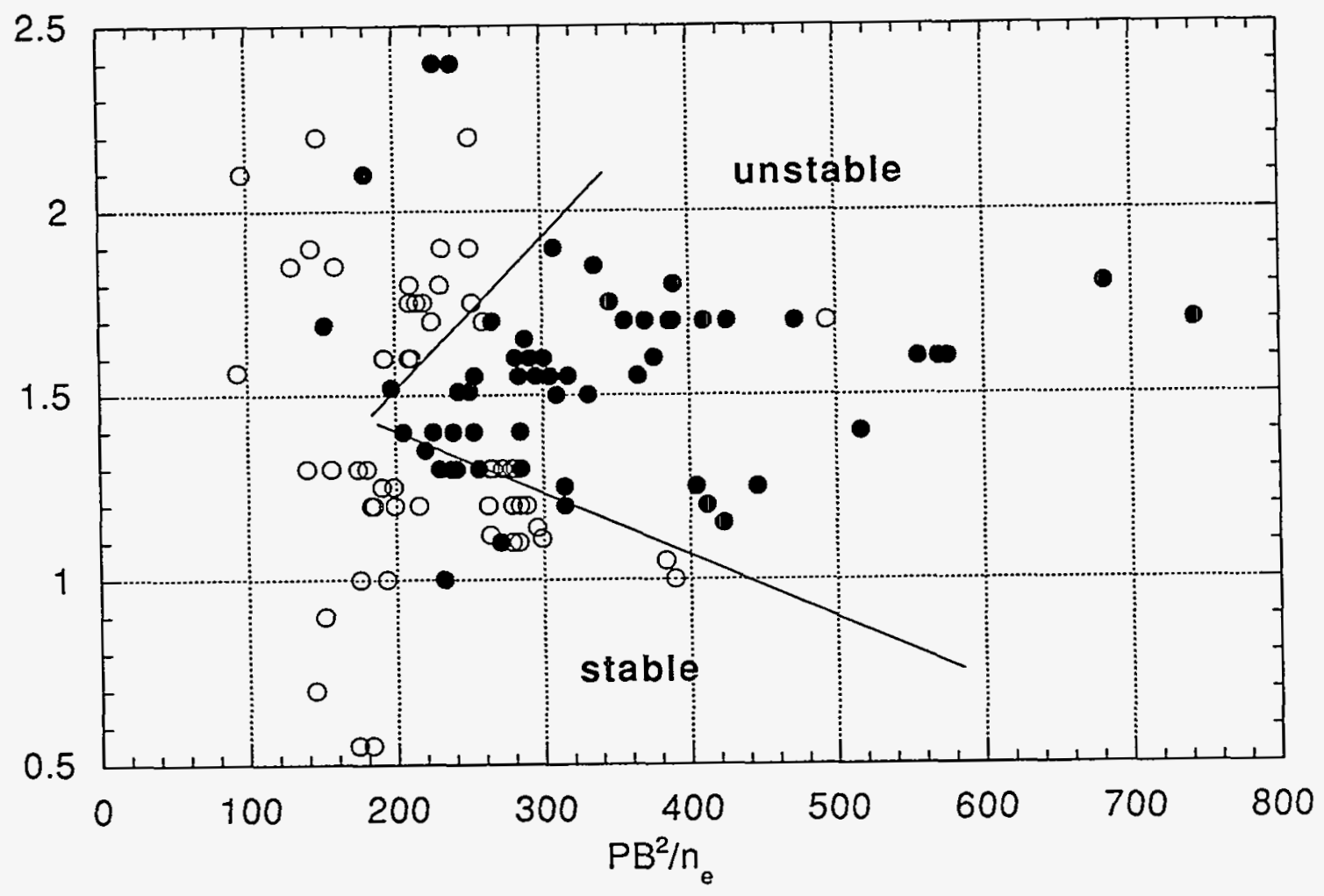

Fig.7 


\section{Horizontal SXR camera (Shot \# 306066)}

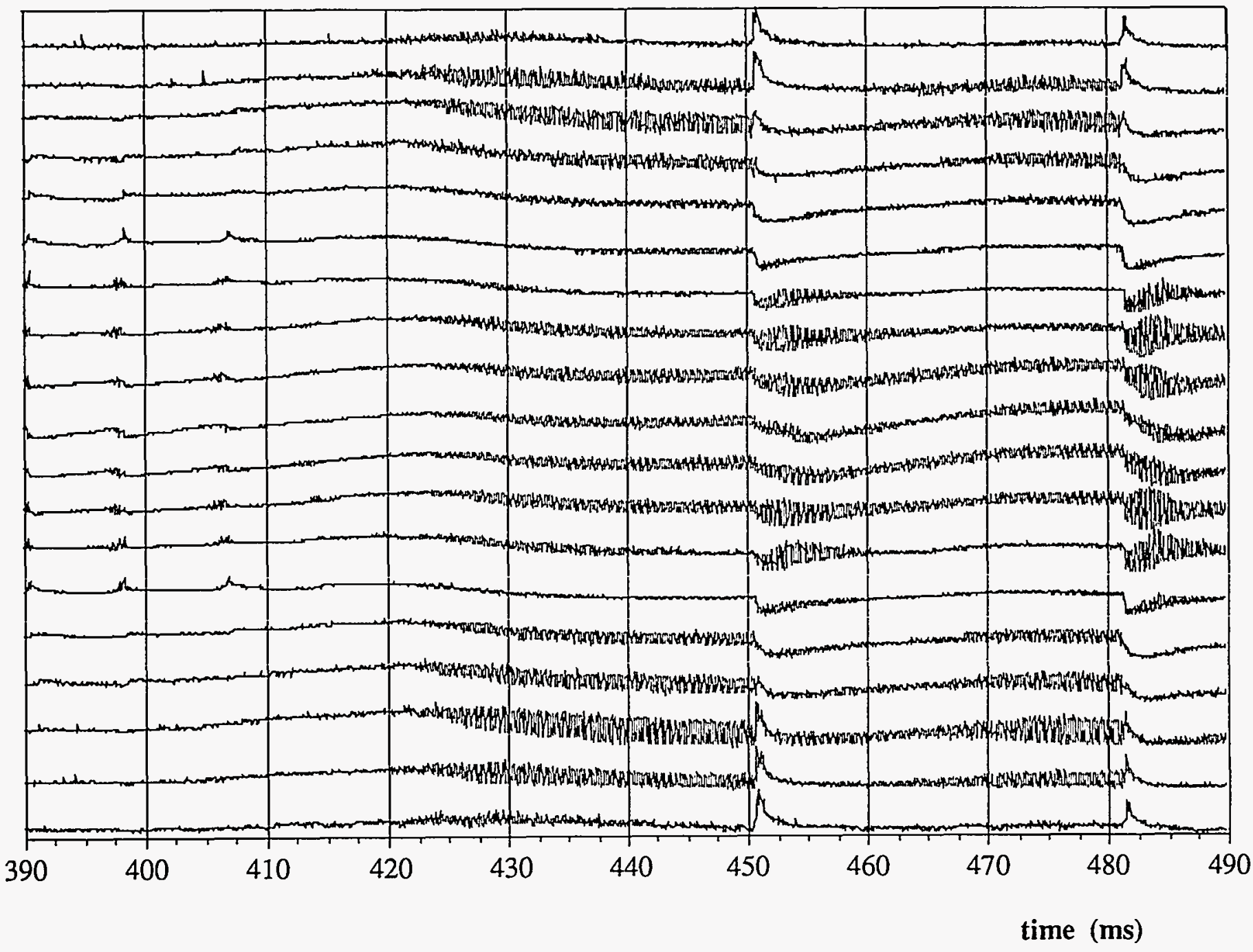

\section{Fig.8}


SXR normalized amplitudes (\# 306066)
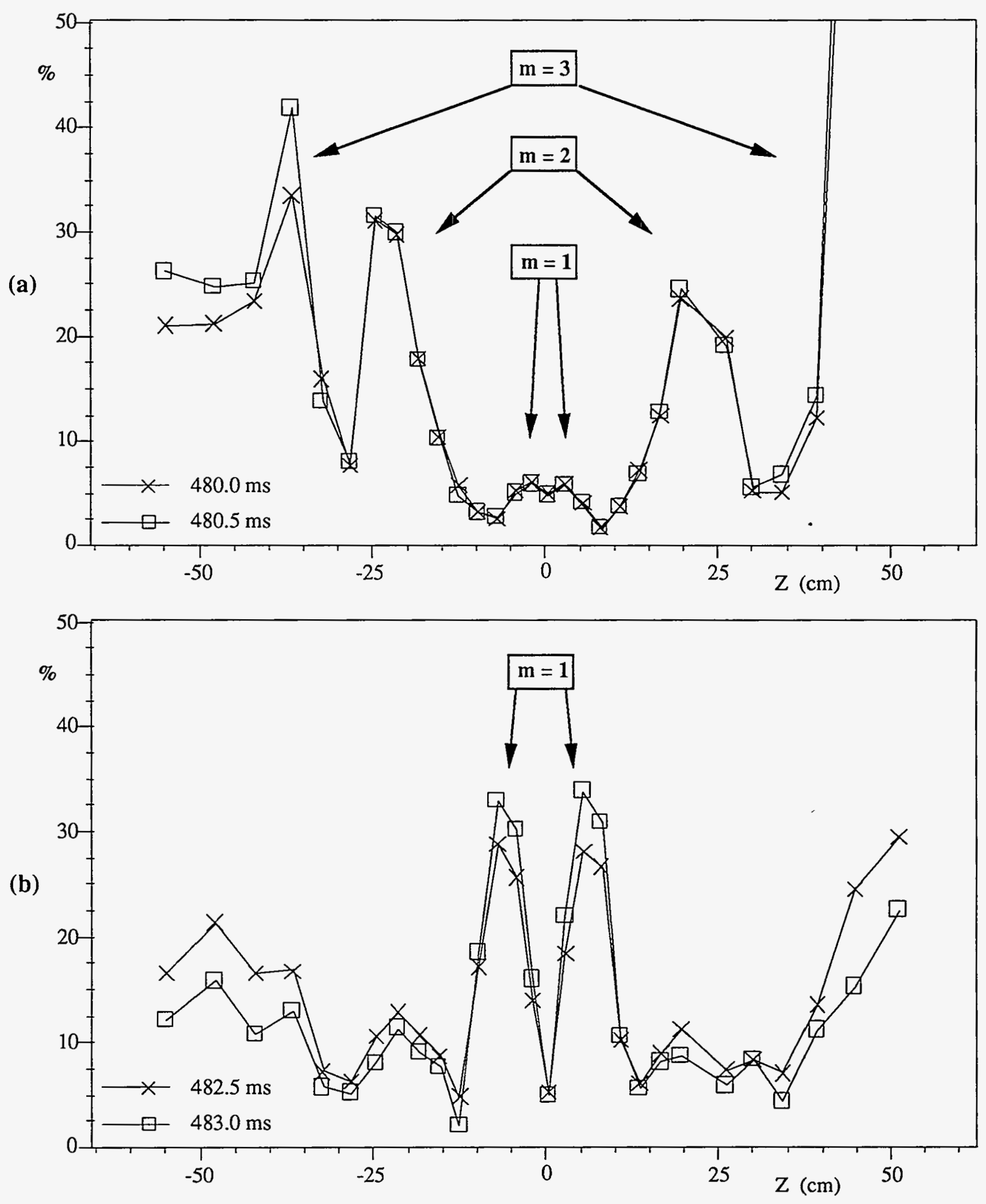

Fig.9 
SXR normalized fluctuations

(a)

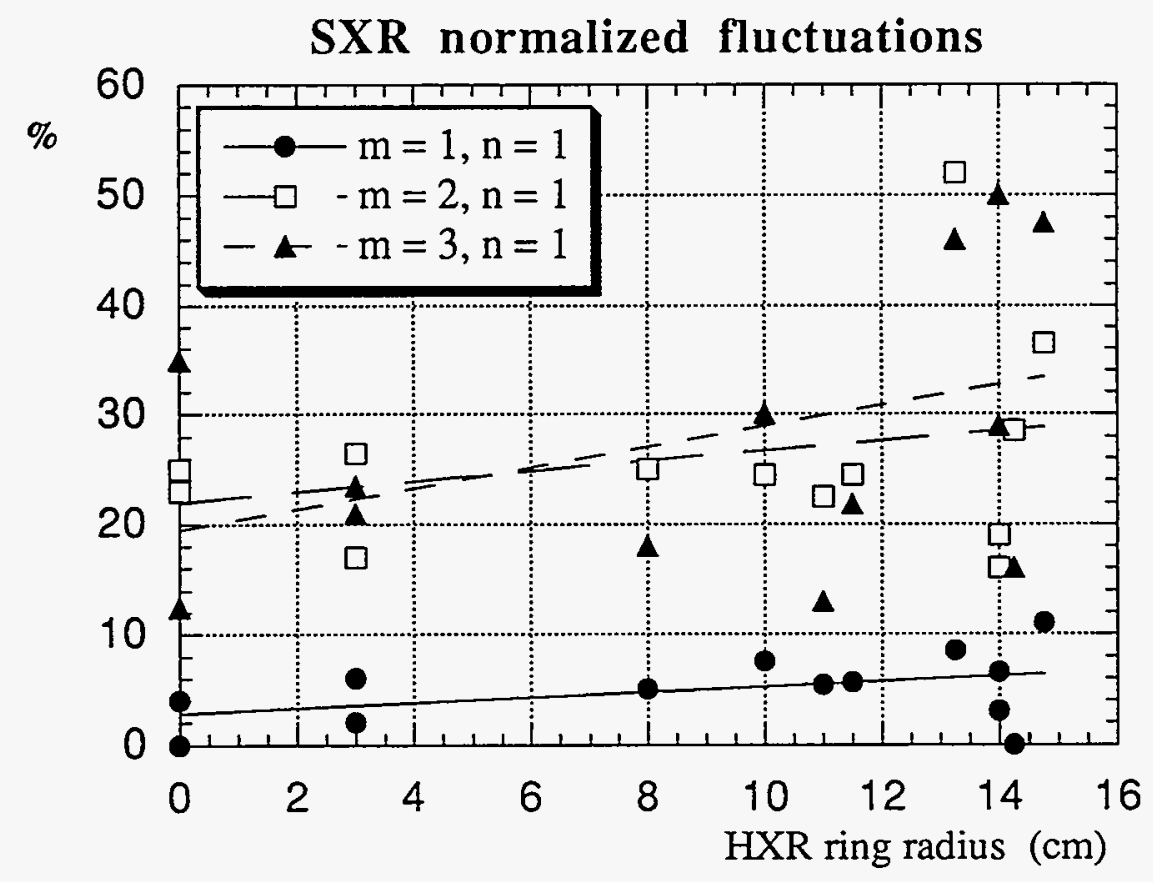

(b)

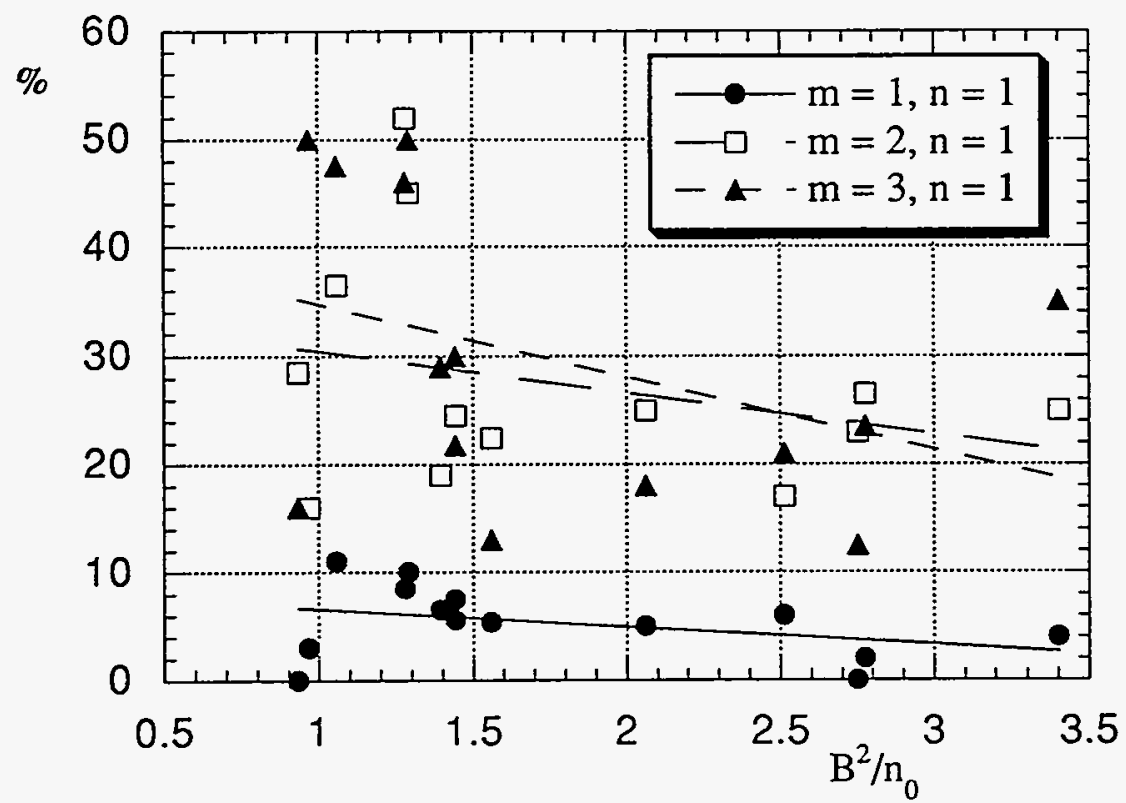

Fig.10 


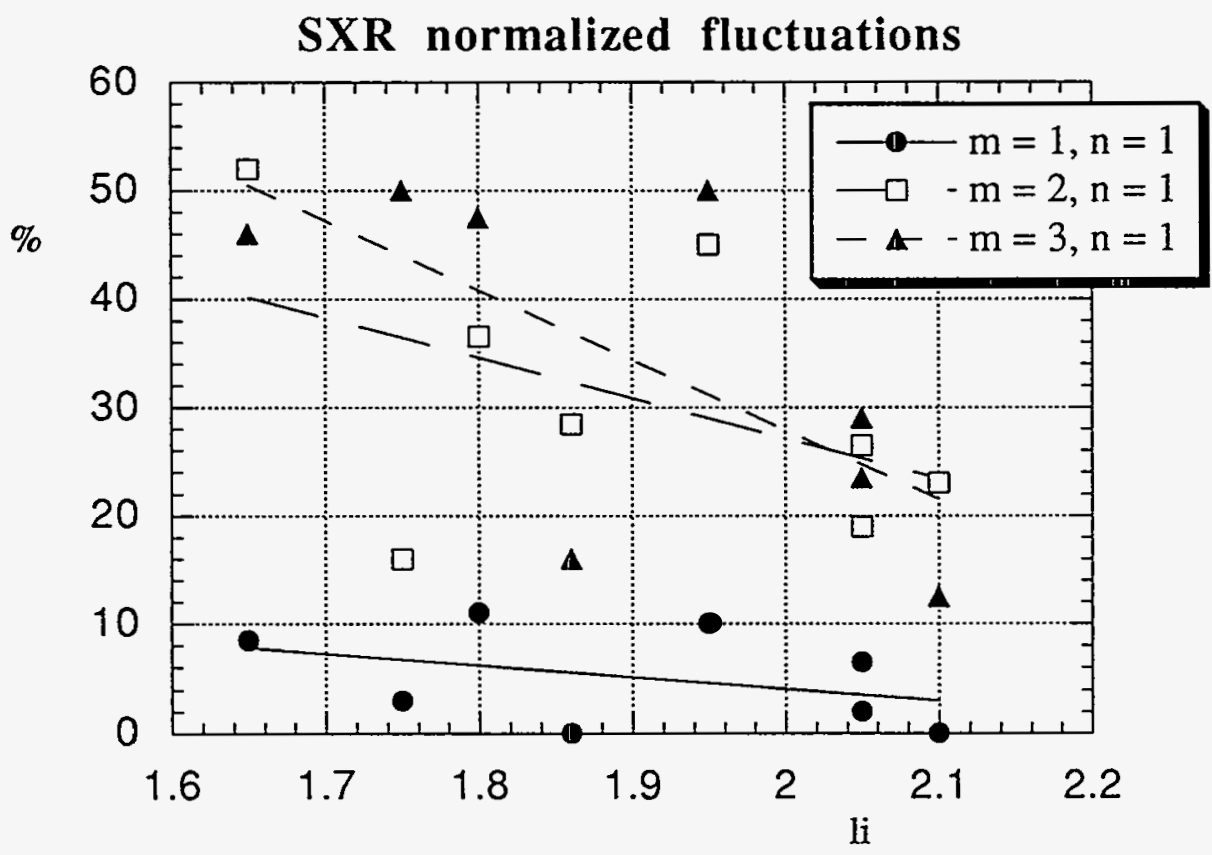

Fig.11 


\section{SXR emissivity profiles (\# 306066)}

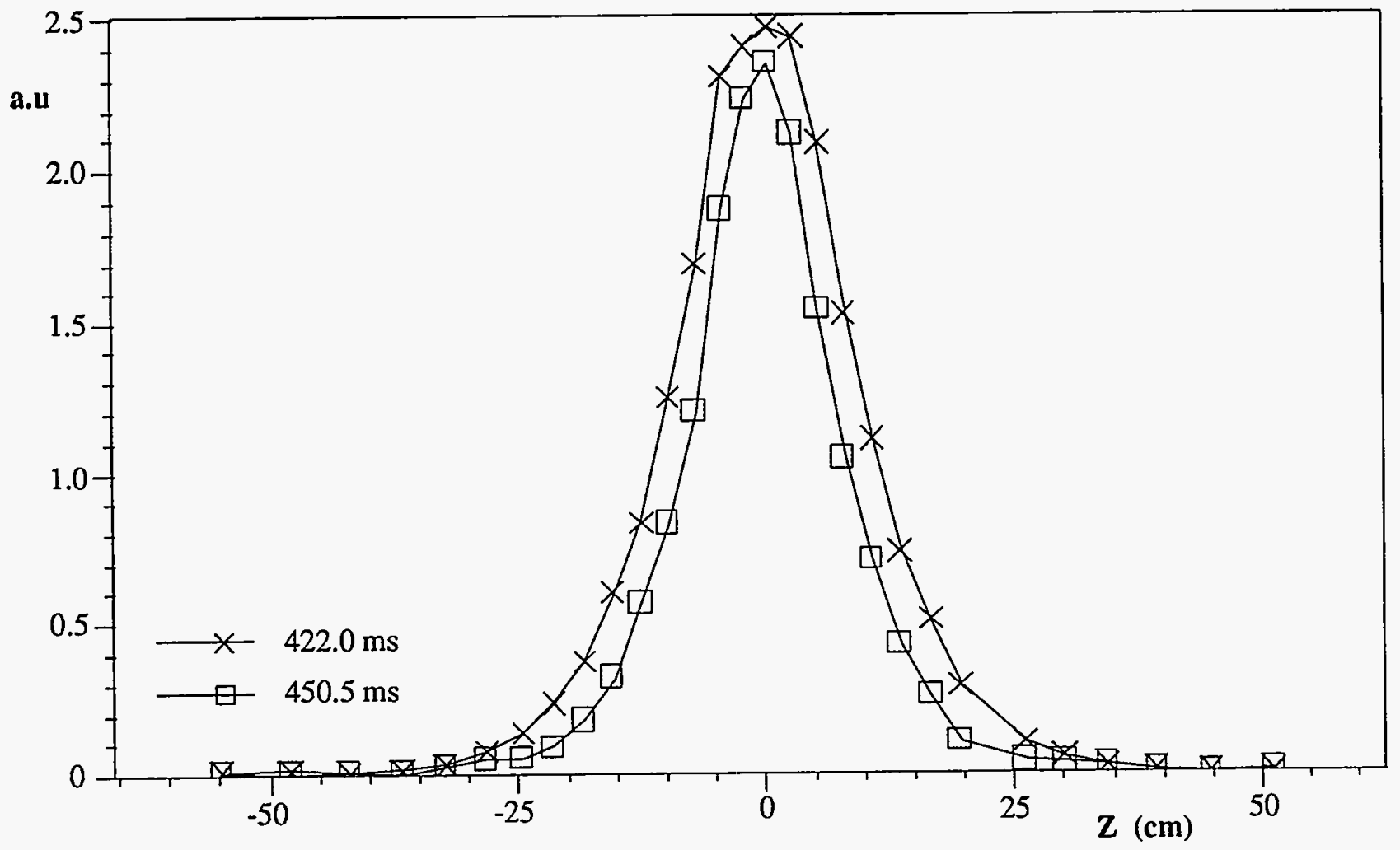

Fig.12 
(a)

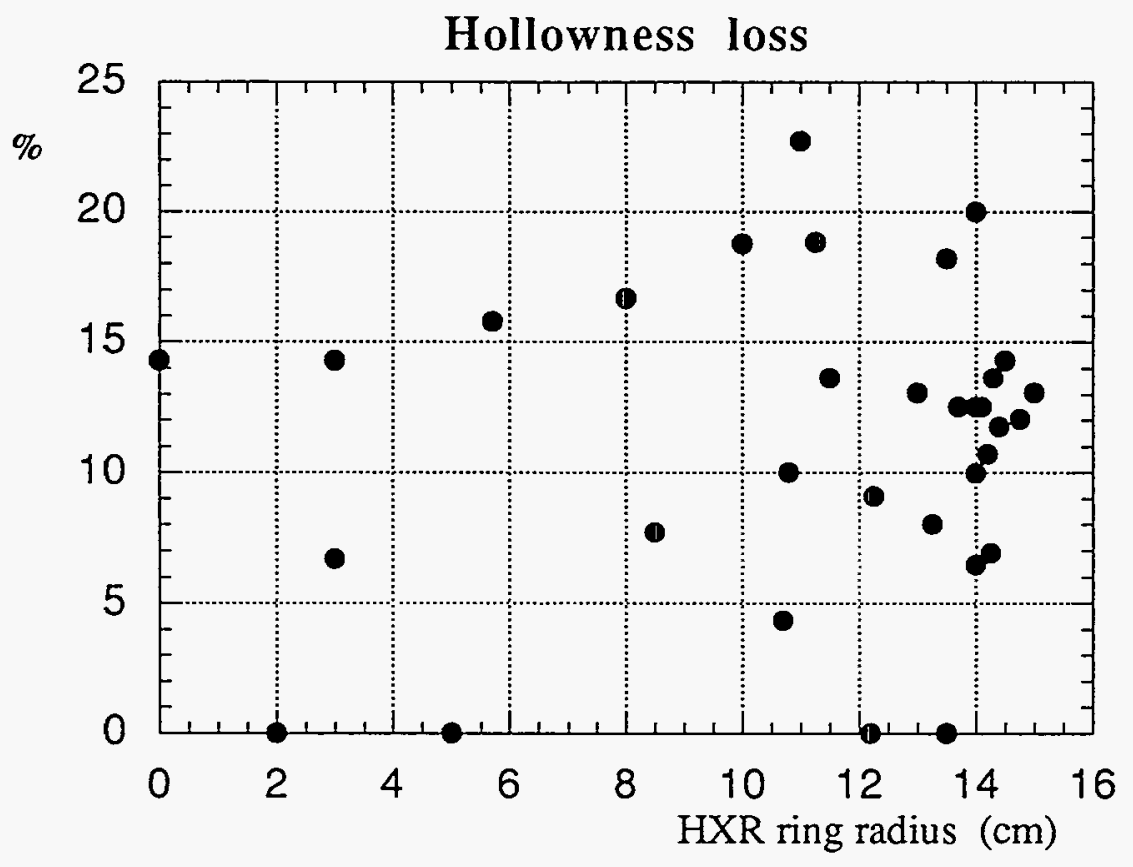

(b)

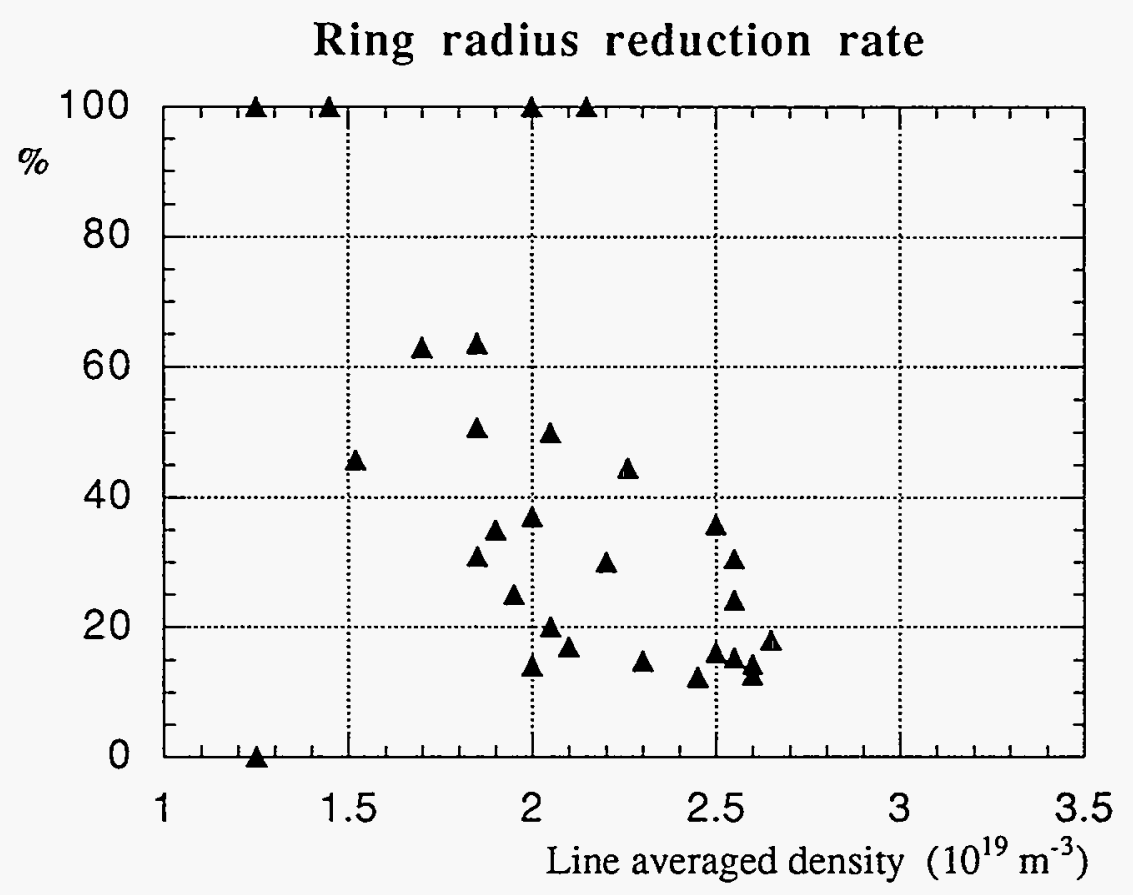

Fig.13 
(a)

(b)
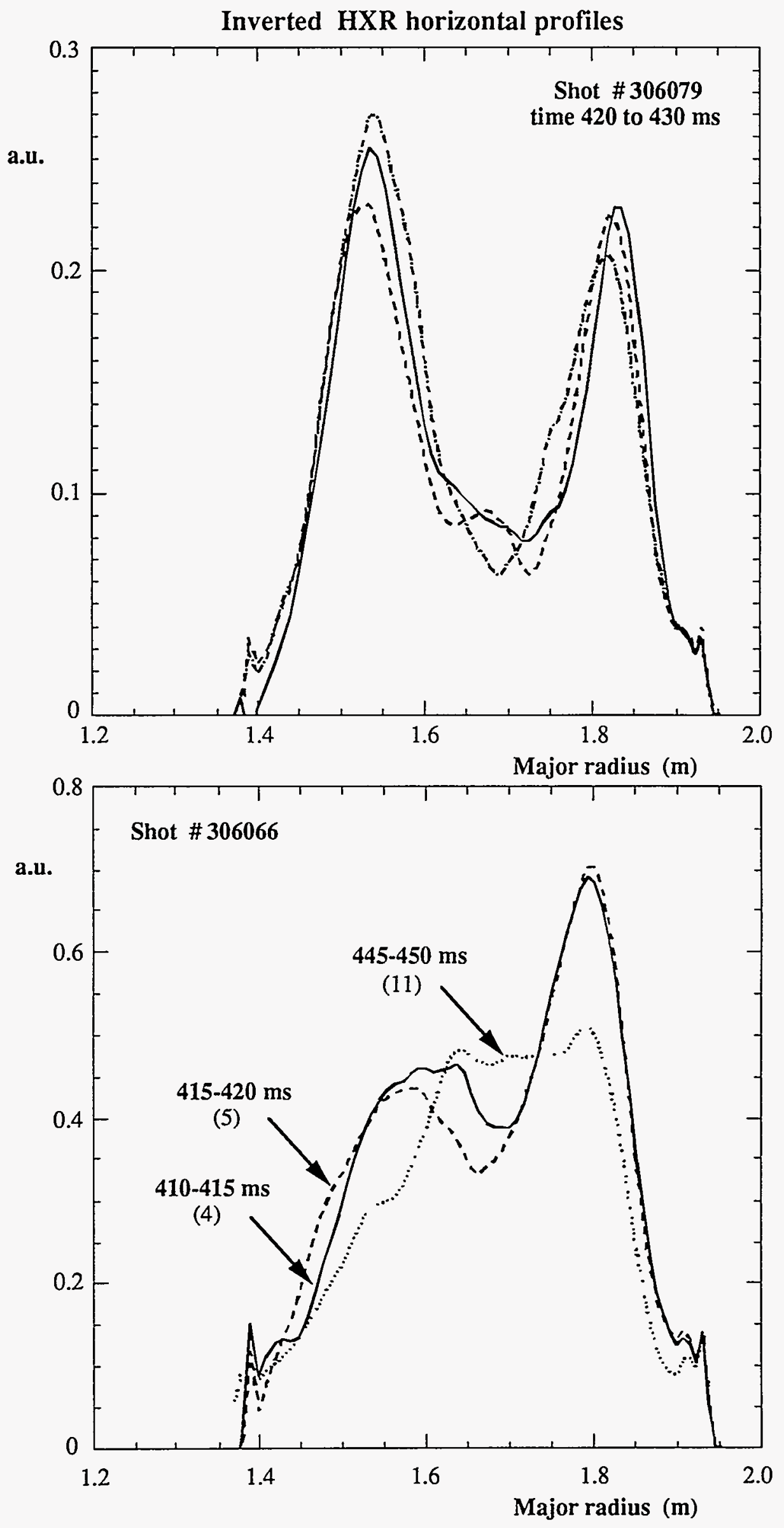

Fig.14 
Dr. F. Paoloni, Univ. of Wollongong, AUSTRALIA

Prof. R.C. Cross, Univ. of Sydney, AUSTRALIA

Plasma Research Lab., Australian Nat. Univ., AUSTRALIA

Prof. I.R. Jones, Flinders Univ, AUSTRALIA

Prof. F. Cap, Inst. for Theoretical Physics, AUSTRIA

Prof. M. Heindler, Institut für Theoretische Physik, AUSTRIA

Prof. M. Goossens, Astronomisch Instituut, BELGIUM

Ecole Royale Militaire, Lab. de Phy. Plasmas, BELGIUM

Commission-European, DG. XII-Fusion Prog., BELGIUM

Prof. R. Bouciqué, Rijksuniversiteit Gent, BELGIUM

Dr. P.H. Sakanaka, Instituto Fisica, BRAZIL

Prof. Dr. I.C. Nascimento, Instituto Fisica, Sao Paulo, BRAZIL Instituto Nacional De Pesquisas Espaciais-INPE, BRAZIL Documents Office, Atomic Energy of Canada Ltd., CANADA Ms. M. Morin, CCFMTokamak de Varennes, CANADA

Dr. M.P. Bachynski, MPB Technologies, Inc., CANADA

Dr. H.M. Skarsgard, Univ. of Saskatchewan, CANADA

Prof. J. Teichmann, Univ. of Montreal, CANADA

Prof. S.R. Sreenivasan, Univ. of Calgary, CANADA

Prof. T.W. Johnston, INRS-Energie, CANADA

Dr. R. Bolton, Centre canadien de fusion magnétique, CANADA

Dr. C.R. James, Univ. of Alberta, CANADA

Dr. P. Lukác, Komenského Universzita, CZECHO-SLOVAKIA

The Librarian, Culham Laboratory, ENGLAND

Library, R61, Rutherford Appleton Laboratory, ENGLAND

Mrs. S.A. Hutchinson, JET Library, ENGLAND

Dr. S.C. Sharma, Univ. of South Pacific, FIJI ISLANDS

P. Mähönen, Univ. of Helsinki, FINLAND

Prof. M.N. Bussac, Ecole Polytechnique, FRANCE

C. Mouttet, Lab. de Physique des Milieux lonisés, FRANCE

J. Radet, CEN/CADARACHE - Bat 506, FRANCE

Prof. E. Economou, Univ. of Crete, GREECE

Ms. C. Rinni, Univ. of loannina, GREECE

Preprint Library, Hungarian Academy of Sci., HUNGARY

Dr. B. DasGupta, Saha Inst. of Nuclear Physics, INDIA

Dr. P. Kaw, Inst. for Plasma Research, INDIA

Dr. P. Rosenau, Israel Inst. of Technology, ISRAEL

Librarian, Intemational Center for Theo Physics, ITALY

Miss C. De Palo, Associazione EURATOM-ENEA, ITALY

Dr. G. Grosso, Istituto di Fisica del Plasma, ITALY

Prof. G. Rostangni, Istituto Gas lonizzati Del Cnr, ITALY
Dr. H. Yamato, Toshiba Res \& Devel Center, JAPAN

Prof. I. Kawakami, Hiroshima Univ., JAPAN

Prof. K. Nishikawa, Hiroshima Univ., JAPAN

Librarian, Naka Fusion Research Establishment, JAERI, JAPAN

Director, Japan Atomic Energy Research Inst., JAPAN

Prof. S. Itoh, Kyushu Univ., JAPAN

Research Info. Ctr., National Instit. for Fusion Science, JAPAN

Prof. S. Tanaka, Kyoto Univ., JAPAN

Library, Kyoto Univ., JAPAN

Prof. N. Inoue, Univ. of Tokyo, JAPAN

Secretary, Plasma Section, Electrotechnical Lab., JAPAN

Dr. O. Mitarai, Kumamoto Inst. of Technology, JAPAN

Dr. G.S. Lee, Korea Basic Sci. Ctr., KOREA

J. Hyeon-Sook, Korea Atomic Energy Research Inst., KOREA

D.I. Choi, The Korea Adv. Inst. of Sci. \& Tech., KOREA

Prof. B.S. Liley, Univ. of Waikato, NEW ZEALAND

Inst of Physics, Chinese Acad Sci PEOPLE'S REP. OF CHINA Library, Inst. of Plasma Physics, PEOPLE'S REP. OF CHINA

Tsinghua Univ. Library, PEOPLE'S REPUBLIC OF CHINA

Z. Li, S.W. Inst Physics, PEOPLE'S REPUBLIC OF CHINA

Prof. J.A.C. Cabral, Instituto Superior Tecnico, PORTUGAL

Prof. M.A. Hellberg, Univ. of Natal, S. AFRICA

Prof. D.E. Kim, Pohang Inst. of Sci. \& Tech., SO. KOREA

Prof. C.I.E.M.A.T, Fusion Division Library, SPAIN

Dr. L. Stenflo, Univ. of UMEA, SWEDEN

Library, Royal Inst. of Technology, SWEDEN

Prof. H. Wilhelmson, Chalmers Univ. of Tech., SWEDEN

Centre Phys. Des Plasmas, Ecole Polytech, SWITZERLAND Bibliotheek, Inst. Voor Plasma-Fysica, THE NETHERLANDS

Asst. Prof. Dr. S. Cakir, Middle East Tech. Univ., TURKEY

Dr. V.A. Glukhikh,Sci. Res. Inst. Electrophys.I Apparatus, USSR

Dr. D.D. Ryutov, Siberian Branch of Academy of Sci., USSR

Dr. G.A. Eliseev, I.V. Kurchatov Inst., USSR

Librarian, The Ukr.SSR Academy of Sciences, USSR

Dr. L.M. Kovizhnykh, Inst. of General Physics, USSR

Kemforschungsanlage GmbH, Zentralbibliothek, W. GERMANY

Bibliothek, Inst. Für Plasmaforschung, W. GERMANY

Prof. K. Schindler, Ruhr-Universitát Bochum, W. GERMANY

Dr. F. Wagner, (ASDEX), Max-Planck-Institut, W. GERMANY

Librarian, Max-Planck-Institut, W. GERMANY 